\title{
NMDA receptors mediate synaptic depression, but not spine loss in the dentate gyrus of adult amyloid Beta (AB) overexpressing mice
}

\author{
Michaela Kerstin Müller ${ }^{1}$, Eric Jacobi ${ }^{1}$, Kenji Sakimura ${ }^{3}$, Roberto Malinow ${ }^{4}$ and Jakob von Engelhardt ${ }^{1,2^{*}}$ (D)
}

\begin{abstract}
Amyloid beta (Aß)-mediated synapse dysfunction and spine loss are considered to be early events in Alzheimer's disease (AD) pathogenesis. $\mathrm{N}$-methyl-D-aspartate receptors (NMDARs) have previously been suggested to play a role for Amyloid beta $(A \beta)$ toxicity. Pharmacological block of NMDAR subunits in cultured neurons and mice suggested that NMDARs containing the GluN2B subunit are necessary for A $\beta$-mediated changes in synapse number and function in hippocampal neurons. Interestingly, NMDARs undergo a developmental switch from GluN2B- to GluN2A-containing receptors. This indicates different functional roles of NMDARs in young mice compared to older animals. In addition, the lack of pharmacological tools to efficiently dissect the role of NMDARs containing the different subunits complicates the interpretation of their specific role. In order to address this problem and to investigate the specific role for $A \beta$ toxicity of the distinct NMDAR subunits in dentate gyrus granule cells of adult mice, we used conditional knockout mouse lines for the subunits GluN1, GluN2A and GluN2B. AB-mediated changes in synaptic function and neuronal anatomy were investigated in several-months old mice with virus-mediated overproduction of $A \beta$ and in 1year old 5XFAD mice. We found that all three NMDAR subunits contribute to the A $\beta$-mediated decrease in the number of functional synapses. However, NMDARs are not required for the spine number reduction in dentate gyrus granule cells after chronic A $\beta$-overproduction in 5xFAD mice. Furthermore, the amplitude of synaptic and extrasynaptic NMDAR-mediated currents was reduced in dentate gyrus granule of 5XFAD mice without changes in current kinetics, suggesting that a redistribution or change in subunit composition of NMDARs does not play a role in mediating Amyloid beta (A $\beta$ ) toxicity. Our study indicates that NMDARs are involved in AD pathogenesis by compromising synapse function but not by affecting neuron morphology.
\end{abstract}

Keywords: NMDA receptor, Amyloid Beta, Alzheimer's disease, GluN2B, GluN2A

\section{Introduction}

Amyloid beta $(A \beta)$ deposition in the brain of Alzheimer Disease (AD) patients initiates a cascade of events that trigger synaptic dysfunction, spine loss and ultimately neuronal death (reviewed in [26]). Indeed, the amount of soluble $A \beta$ correlates highly with the state of cognitive impairment in $\mathrm{AD}$ patients [49, 52, 58, 97]. However,

\footnotetext{
* Correspondence: engelhardt@uni-mainz.de

${ }^{1}$ Institute of Pathophysiology, University Medical Center of the Johannes

Gutenberg University Mainz, 55128 Mainz, Germany

${ }^{2}$ Synaptic Signalling and Neurodegeneration, German Center for

Neurodegenerative Diseases (DZNE), 53127 Bonn, Germany

Full list of author information is available at the end of the article
}

despite intense research, it is not well understood how $A \beta$ induces early disease pathologies.

Several studies suggested that $A \beta$-toxicity is mediated via an influence on NMDAR function or expression [29, 36, 37, 79]. NMDARs are known to play an important role for synaptic plasticity in the healthy brain (reviewed in [88]). Therefore, it has been speculated that altered NMDAR signalling is involved in the pathogenesis of several neurological diseases including AD (reviewed in [42]). Consistently, one of the two types of FDA (U.S. Food and Drug Administration) approved AD therapies targets NMDARs. Thus, the partial NMDAR antagonist Memantine alleviates cognitive impairments in

(C) The Author(s). 2018 Open Access This article is distributed under the terms of the Creative Commons Attribution 4.0 International License (http://creativecommons.org/licenses/by/4.0/), which permits unrestricted use, distribution, and 
moderate-severe AD patients $[68,73,83,100]$. However, antagonists that are selective for specific NMDAR subunits would be more effective as $\mathrm{AD}$ treatment than the unselective blocker Memantine.

NMDARs are tetramers composed of two obligatory GluN1 subunits and combinations of subunits GluN2A-D and/or GluN3A-B subunits [12, 39, 56]. NMDARs containing different GluN2 subunits differ in their expression profile and function [57, 91, 97]. GluN1, GluN2A and GluN2B are the predominant subunits that are expressed in excitatory neurons of the adult rodent forebrain [57, 98], forming diheteromeric GluN1/GluN2A- and GluN1/GluN2B- as well as triheteromeric GluN1/GluN2A/GluN2B containing NMDARs [50, 77, 86]. The GluN2A subunit is postnatally upregulated [57] and thought to be the major synaptic subunit of homomeric NMDARs of excitatory forebrain neurons in adult mice. In contrast, the GluN2B subunit is also expressed in forebrain neurons of newborn mice, but thought to be present in the majority of extrasynaptic NMDARs [18, 24, 27, 63, 87]. The activation of synaptic NMDARs has been shown to exert protective function [25]. In contrast, activation of extrasynaptic NMDARs activates apoptotic signalling cascades $[25,78]$.

It has been shown that the GluN2B subunit is involved in the $A \beta$-mediated synaptic dysfunction and spine loss of cultured neurons [7, 30, 40, 74, 79]. However, studies on $\mathrm{A} \beta$-toxicity in cultured neurons that are prepared from newborn mice may well overestimate the contribution of the GluN2B subunit since they predominantly express this subunit $[55,91,92]$. However, blockade of NMDARs with ifenprodil or radiprodil, antagonists specific for diheteromeric GluN1/GluN2B-containing NMDARs, or deletion of the GluN2B subunit rescued $A \beta$-induced long-term-potentiation (LTP) deficits [31, 64-66, 70]. This suggests that the GluN2B subunit plays a role for $\mathrm{A} \beta$-toxicity also in the adult brain. It remains to be shown if the GluN2B subunit is also involved in other alterations that are known to be mediated by $A \beta$-overproduction like changes in basal synaptic function and in the morphology of neurons such as in spine loss, since contrasting data have been published [30, 41, 66, 79, 82].

Little is known about the mechanisms how NMDARs are involved in $A \beta$-toxicity. Several mechanisms have been proposed including that $A \beta$ may directly bind to NMDARs and influence their gating $[14,43]$. Additionally, A $\beta$-mediated Calcium-influx via NMDARs leads to the formation of reactive oxygen species (ROS) and initializes oxidative stress [13]. An alternative hypothesis suggests that an $\mathrm{A} \beta$-mediated redistribution of NMDARs may increase the vulnerability of neurons to higher extracellular glutamate levels, similar to what has been shown for Huntington's disease [53]. Thus, a relative upregulation of the number of extrasynaptic GluN2B-containig NMDARs, which activate apoptotic pathways [47, 71, 87], and downregulation of, eventually more neuroprotective, synaptic GluN2A-containing NMDARs [8, 47, 89], could explain an increased susceptibility to excitotoxicity. A $\beta$ indeed decreases NMDAR expression on the cell surface of neurons from post-mortem AD patients [33, 35, 54, 72]. However, it is not clear which NMDAR subunit is affected, whether synaptic or extrasynaptic NMDARs are downregulated, and finally if $A \beta$ induces changes in NMDAR distribution in the adult brain.

To investigate the role of NMDARs for A $\beta$-toxicity in adult mice, we used conditional NMDAR knockout mice. Changes in synaptic function and neuronal morphology in response to subacute $A \beta$-overproduction was investigated by a virus-mediated expression of $A \beta$ for several weeks in dentate gyrus (DG) granule cells of adult mice. The DG was chosen as region of interest, since LTP, which is inhibited by A $\beta$, occurs in CA1 and DG. Since A $\beta$ plaques form in the DG before they appear in CA1 area, we focused on this brain area. The influence of chronic $A \beta$ overproduction was investigated in 1-year old 5xFAD mice. We found that NMDARs indeed play a major role for the influence of $A \beta$ on the number of functional synapses, but not on the $\mathrm{A} \beta$-mediated change in spine number after chronic $A \beta$ overproduction. Moreover, $A \beta$ reduces the expression of NMDARs at both synaptic and extrasynaptic sites without a major influence on subunit composition.

\section{Material \& Methods \\ Animals}

Mouse experiments were performed according to the German Animal Welfare Act and the Regierungspräsidium Karlsruhe as well as the Landesuntersuchungsamt Rhineland-Palatinate. All procedures followed the "Principles of laboratory animal care" (NIH publication No. 86-23, revised 1985). Mice had access to food and water ad libitum. The conditional NMDAR knockout mouse lines GluN1 ${ }^{\mathrm{fl} / \mathrm{fl}}$ [59], GluN2A ${ }^{\mathrm{f} / \mathrm{fl}}[19]$ and GluN2B ${ }^{\mathrm{f} / \mathrm{fl}}[60,93]$, in which the grin 1 , grin $2 a$ and grin $2 b$ genes are flanked by loxP sites, were used for conditional deletion of the different NMDAR subunits. Mice of both sexes were used. The 5xFAD mouse line [60] was used as a mouse model for $A D$ and crossbred with the conditional NMDAR knockout mice lines. Only female mice were used from these mouse lines. Deletion of NMDAR subunits in the conditional knockout mice was achieved by injection of recombinant adeno-associated viruses (rAAVs) expressing Cre-recombinase into the DG (rAAV-Syn-Cre-T2A-EGFP).

\section{rAAV production and stereotactic injection}

pAAV-CaMKII-T2A-tdTom plasmid was used to subclone A $\beta$ overexpressing DNA (C-terminal 100 (CT100)) from a sindbis virus backbone [36] in an rAAV vector. 
A mutated CT100 DNA construct containing an isoleucine to phenylalanine switch at amino acid position 716 , named CT100(I716F), was constructed via site-directedmutagenesis (Quik Change II kit from Agilent Technologies, USA) from the pAAV-CaMKII-CT100-T2A-tdTom plasmid to produce pAAV-CaMKII-CT100(I716F)T2A-tdTom for increased $A \beta_{42 / 40}$ overexpression [21]. The following constructs were expressed in rAAVs and used in the study: rAAV-CaMKII-tdTom (control cells), rAAV-CaMKII-CT100/CT100(I716F)-T2A-tdTom (CT100 or CT100(I716F) overexpression), rAAV-Syn-Cre-T2A-GFP (NMDAR subunit deletion) and rAAV-Syn-Cre-T2A-GFP + rAAV-CaMKII-CT100/ CT100(I716F)-T2A-tdTom (NMDAR subunit deletion and CT100 or CT100(I716F) overexpression) (Fig. 1b and Additional file 1: S1b). Co-injection of controland Cre-expressing-rAAVs could thus be differentiated by red and green fluorescence (Fig. 1a).

Plasmids used for rAAV1/2 production were amplified with the Qiagen Maxi Kit Plus (Qiagen, Germany). HEK293T cells were transfected with the DNA plasmids with a standard $\mathrm{CaCl}_{2}$ transfection protocol and the rAAV was purified via heparin columns (GE Healthcare, England) using standard procedures.

rAAVs were stereotactically injected into the DG through a thin glass capillary using the following coordinates according to bregma: anteroposterior, $-3 \mathrm{~mm}$; mediolateral, $\pm 3 \mathrm{~mm}$; dorsoventral, $-3.5 \mathrm{~mm}$ from the skull surface.

\section{Preparation of acute slices}

Mice were deeply anesthetized with $3 \%$ isoflurane and cardially perfused with ice-cold slicing solution $(212 \mathrm{mM}$ sucrose, $26 \mathrm{mM} \mathrm{NaHCO} 3,1.25 \mathrm{mM} \mathrm{NaH} \mathrm{PO}_{4}, 3 \mathrm{mM} \mathrm{KCl}$, $0.2 \mathrm{mM} \mathrm{CaCl}_{2}, 7 \mathrm{mM} \mathrm{MgCl}$ and $10 \mathrm{mM}$ glucose). Brains were quickly removed and $250 \mu \mathrm{m}$ thick acute transverse slices were cut in ice-cold slicing Solution with the help of a tissue slicer (slicer: Sigmann Elektronik, Germany; razor blade: Personna, USA). Acute brain slices were immediately transferred to a slice holding chamber with $37{ }^{\circ} \mathrm{C}$ ACSF $(125 \mathrm{mM} \mathrm{NaCl}, 25 \mathrm{mM} \mathrm{NaHCO}, 1.25 \mathrm{mM}$ $\mathrm{NaH}_{2} \mathrm{PO}_{4}, 2.5 \mathrm{mM} \mathrm{KCl}, 2 \mathrm{mM} \mathrm{CaCl} 2,1 \mathrm{mM} \mathrm{MgCl}$ and $25 \mathrm{mM}$ glucose) and incubated for $15 \mathrm{~min}$. The holding chamber was slowly cooled down to RT and slices were incubated for $45 \mathrm{~min}$ before being used in experiments.

\section{Electrophysiology}

Acute transverse slices were completely submerged and continuously perfused with carbogen-saturated artificial cerebral spine fluid (ACSF, see supplemental methods) at RT with a flow-rate of $1 \mathrm{ml} / \mathrm{min}$. Slices were imaged with an Olympus BX51WI upright microscope (Olympus, Japan) fitted with a $4 \times$ air (Plan N, NA 0.1; Olympus, Japan) and 40× water-immersion (LUMPlan FI/IR, NA 0.8w; Olympus, Japan) objective. Electrical signals were acquired at $10 \mathrm{kHz}$ for miniature excitatory post-synaptic current (mEPSC) recordings and $50 \mathrm{kHz}$ for all other recordings using an EPC10 amplifier (HEKA, Germany), connected to a probe and PC. Electrical signals were recorded with the help of Patchmaster software (HEKA, Germany). No correction for liquid junction potential was done. For $\mathrm{A} / \mathrm{N}$ ratios, paired pulse ratio recordings and firing patterns, $10 \mu \mathrm{M}$ SR95531 hydrobromide (Biotrend, Germany) were added to the ACSF. $1 \mu \mathrm{M}$ TTX (Biotrend, Germany) and $50 \mu \mathrm{M}$ APV (Biotrend, Germany) were additionally added in mEPSC recordings. For NMDAR decay experiments $10 \mu \mathrm{M}$ SR95531 hydrobromide was added with $50 \mu \mathrm{M}$ CNQX.

For extracellular stimulation of the medial perforant path, the stimulus was generated by a stimulus isolator (WPI, USA) connected with the EPC10 amplifier and triggered by the Patchmaster software. A chlorinated silver wire located inside a borosilicate glass capillary filled with ACSF was used as stimulation electrode. For nucleated patches, cells were slowly pulled out of the slice while simultaneously applying negative pressure after reaching the whole cell configuration. Thus, the nucleus covered with cell membrane was pulled out of the slice and navigated in front of a theta glass tubing mounted onto a piezo translator (PI, Germany). A $1 \mathrm{~ms}$ pulse of $1 \mathrm{mM}$ glutamate application solution (in $\mathrm{mM}$ ): 135 $\mathrm{NaCl}, 10 \mathrm{HEPES}, 5.4 \mathrm{KCl}, 1.8 \mathrm{CaCl} 2,5$ glucose, 0.01 CNQX, 0.01 glycine ( $\mathrm{pH} 7.2)$ was applied via one pipe of the theta glass. The other pipe contained the application solution without glutamate.

\section{Morphological analysis}

Cells used for morphological analysis were filled with an intracellular solution containing $0.1-0.5 \%$ biocytin (Sigma Aldrich, USA) through the patch-pipette while recording. Acute slices were fixed in $4 \%$ Histofix (Carl Roth, Germany) after recording. 2-10 days later, slices were washed in $1 \times$ PBS (phosphate buffered saline), permeabilized in $0.2 \%$ PBST $(0.2 \%$ Triton in $1 \times$ PBS) and stained overnight with a Streptavidin-coupled Alexa594-conjugated antibody (life technologies, USA). Slices from 5xFAD mice were additionally stained with an Alexa488-coupled 6E10 Antibody (Covance, USA) for $A \beta$ plaque staining. After washing in $1 \times$ PBS, slices were mounted in ProLong Gold Antifade (life technologies, USA).

Neurons were imaged with a fixed-stage Leica TCS SP5 II microscope (Leica, Germany) and the Leica LAS AF Lite Software (Leica, Germany). Z-stacks from whole neurons were imaged with a $40 \times$ oil-immersion objective (Leica, Germany) with the following parameters: voxel size $x / y=0.758 \mu \mathrm{m}, \mathrm{z}=0.209 \mu \mathrm{m}$. Z-stacks from dendrites were taken with a $63 \times$ oil-immersion objective (Leica, Germany) with the following parameters: voxel size $\mathrm{x} / \mathrm{y}=0.08 \mu \mathrm{m}, \mathrm{z}=0.168 \mu \mathrm{m}$. 


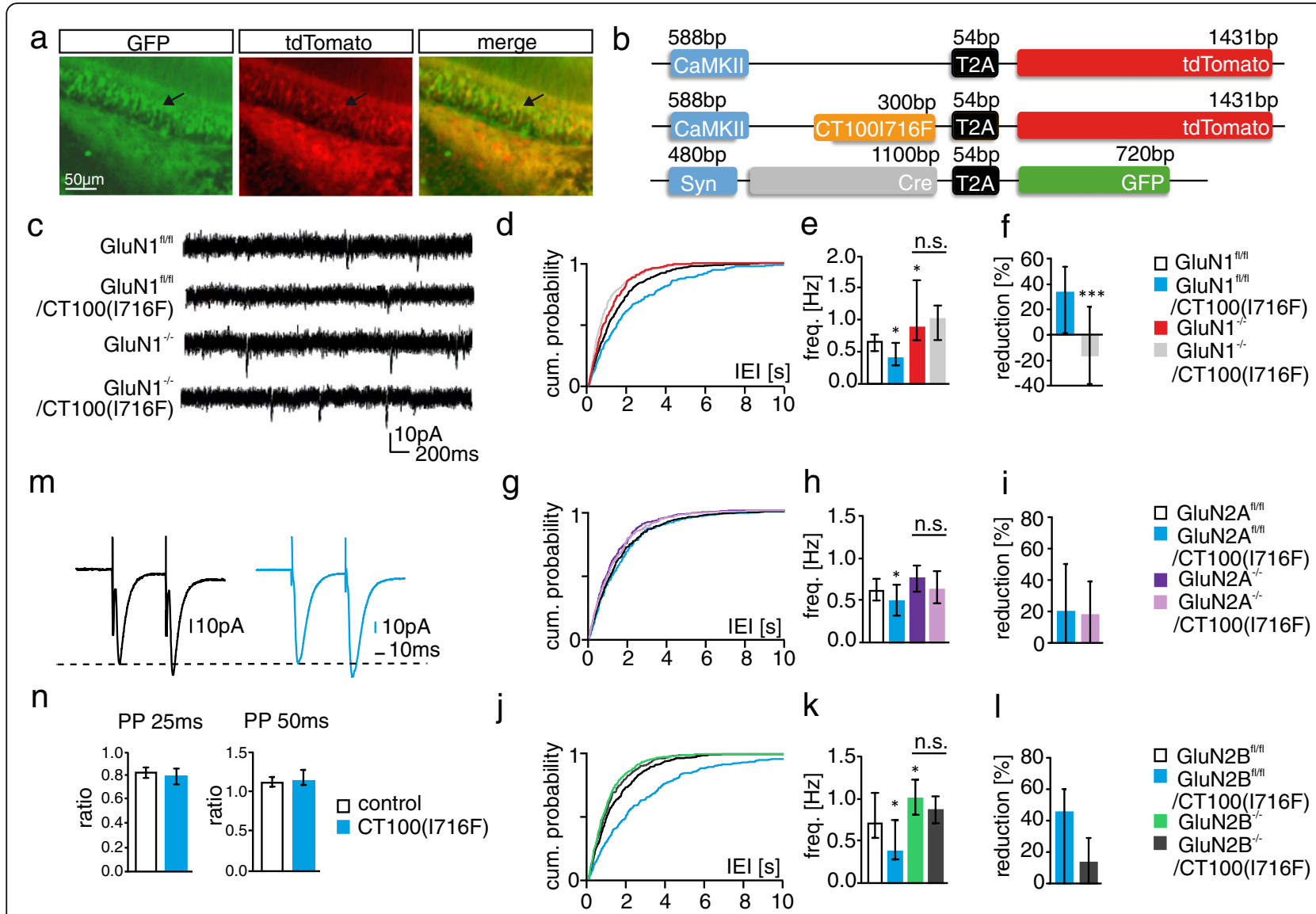

Fig. 1 CT100(1716F)-mediated synaptic depression in granule cells of adult mice is NMDAR dependent. a Double infection with rAAV-Syn-CreT2A-GFP and rAAV-CaMKII-CT100(1716F)-T2A-tdTomato in DG neurons. The arrowhead points to a double-infected DG granule cell. b pAAV constructs were used to express CT100(1716F) or Cre-recombinase or tdTomato as control. c Example traces of mEPSC recordings from GluN ${ }^{f / / f l}$ mice injected with the different AAV constructs as indicated. $\mathbf{d}+\mathbf{e}$ CT100(I716F) increases inter-event-interval (IEI) and reduces mEPSC frequency in DG granule cells in cells of GluN1 ${ }^{\mathrm{fl} / \mathrm{fl}}$ mice. Deletion of GluN1 (GluN1 ${ }^{-1-}$ ) increases mEPSC frequency. Overexpression of CT100(I716F) does not significantly reduce mEPSC frequency in GluN1 ${ }^{-/-}$granule cells. $\mathbf{f}$ To test if the effect of CT100(1716F) in GluN1 $1^{\text {fl/fl }}$ neurons is different from that in

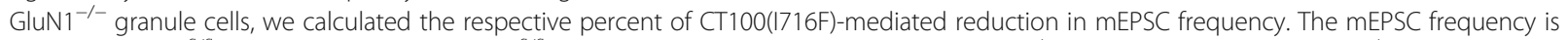
smaller in GluN1/fl/l/CT100(1716F) than in GluN1 $1^{\text {fl/fl }}$ cells (blue bar) and slightly bigger in GluN1 ${ }^{-/-} /$CT100(1716F) than in GluN1 $1^{-/}$cells (gray bar). The reduction in GluN1 ${ }^{\mathrm{fl} / \mathrm{fl}}$ cells is significantly bigger than the effect of CT100(1716F) in GluN1 ${ }^{-/-}$granule cells. $\mathbf{g}+\mathbf{h} \mathrm{CT100}(\mathrm{I} 16 \mathrm{~F})$ reduces $\mathrm{mEPSC}$ frequency in DG granule cells in cells of GluN2A $A^{\mathrm{fl} / \mathrm{fl}}$ mice, but does not significantly reduce mEPSC frequency in GluN2A $\mathrm{A}^{-/-}$granule cells. $\mathbf{i}$ The CT100(I716F)-mediated decrease in mEPSC frequency in GluN2A $A^{\mathrm{flfl} l}$ cells is not significantly different from the decrease in GluN2 $\mathrm{A}^{-/-}$cells. $\mathbf{j}+\mathbf{k}$

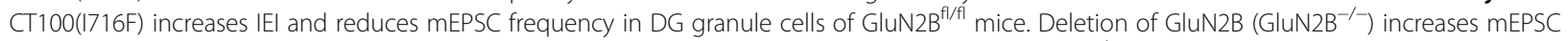

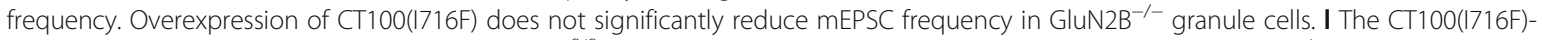

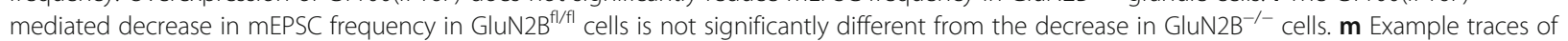
paired-pulse recordings (PPR) with pairs of inter-stimulus intervals (ISI) of 25 ms $\mathbf{n}$ The PPR of the amplitudes of two currents evoked with 25 ms or $50 \mathrm{~ms}$ ISls is not different in control cells and CT100(1716F)-overexpressing cells. ISIs are shown on the top of the quantification. Bar graphs show median \pm IQR. ${ }^{*}=p<0.05,{ }^{* *}=p<0.01,{ }^{* * *}=p<0.001 ;$ cum. $=$ cumulative

Z-stacks of DG granule cells were semi-automatically traced with Neuronstudio (CNIC, Mount Sinai School of Medicine, USA) and Sholl analysis was performed. Dendritic spines were also counted semi-automatically with Neuronstudio.

\section{Analysis and statistics}

Analysis of electrophysiological experiments was carried out using Clampfit (Molecular Devices, USA), IGOR Pro (WaveMetrix, USA), Microsoft Office Excel (Microsoft,
USA) and GraphPad Prism (GraphPad software, USA). For mEPSC analysis, the minianalysis plugin of the Clampfit software was used. For Firing pattern and NMDAR decay analysis, IGOR Pro was used with the Patcher's Power Tools and Neuromatic analysis package (MPI for biophysical chemistry, Germany and Jason Rothman, http://www.neuromatic.thinkrandom.com/). Morphological datasets were analyzed using the NeuronStudio software. Amira (FEI, USA) was used for blind deconvolution to improve image quality for spine analysis. 
Statistics were performed with Graphpad Prism 6 (Graphpad, USA). Sholl analysis was statistically evaluated with a two-way ANOVA (analysis of variance with Tukey test for multiple comparisons). Datasets were tested for statistical significance with Mann-Whitney (MW) or Kruskal-Wallis (followed by Dunn's posttest) tests. Data is depicted as median \pm interquartile ranges (IQR). Sholl analysis is shown as Mean \pm standard error of the mean (SEM). $P$ values $<0.05$ were considered statistically significant $(*=p<0.05, * *=p<0.01, * * *=p<$ 0.001). All figures were prepared with Corel Draw X7 (Corel, Canada).

\section{Results}

NMDARs are involved in CT100-induced changes of synaptic function in young mice

Synaptic dysfunction, one of the earliest events in $\mathrm{AD}$ pathology [51], is thought to be caused by overproduction of toxic $A \beta$ species $[30,95]$. To induce $A \beta$-toxicity, we overexpressed $A \beta$ in the DG of adult mice using a virus-mediated approach. To this end, we injected rAAVs that expressed the penultimate $A \beta$ precursor CT100 (Additional file 1: S1a), which is known to reduce functional synapse number of neurons in organotypic slice cultures [67]. However, CT100 overexpression for three (data not shown, Table 1) and 9-10 weeks (Table 1 and Additional file 1: S1d) did not affect the number of functional synapses in adult mice, as mEPSC frequency in infected granule cells was unaffected compared to that in control cells. This was surprising because CT100 overexpression with a sindbis virus in organotypic slice cultures has been shown to induce synaptic dysfunction $24 \mathrm{~h}$ post infection [36, 67]. Since organotypic brain slices are prepared from newborn mice, we wondered if neurons in the brains of younger mice are more susceptible to $A \beta$-toxicity. We thus injected rAAVs overexpressing CT100 into the DG of young mice (P7) and indeed observed a decrease in mEPSC frequency in CT100-overexpressing cells 9-10 weeks post injection (Table 1 and Additional file 1: S1f), possibly suggesting that $A \beta$-toxicity reduces with brain development. However, infection efficacy and $A \beta$-overproduction may also change with development, which could explain the observed age-dependency.

To investigate the role of NMDARs in $A \beta$-mediated changes in synapse number and function, we deleted NMDARs subunits by injection of a Cre-recombinase expressing rAAV (rAAV-Syn-Cre-T2A-GFP) into the DG of mice, in which the gene encoding the GluN1 subunit (grin1) is flanked by loxP sites (GluN1 $1^{\mathrm{t} / \mathrm{fl}}$ mice). The ratio of NMDAR-mediated to AMPAR-mediated current amplitudes (NMDA/AMPA ratio) was significantly decreased (86.83\%) three weeks post injection, indicating a nearly complete loss of NMDARs (Additional file 2: S4a, b and Table 2).

In the next step, NMDARs were deleted in parallel with overexpression of $A \beta$ to investigate whether NMDARs play a role in $A \beta$-mediated changes in synaptic function in young mice. To this end, one week old GluN1 $1^{\mathbb{t} / 1 / 1}$ mice were injected with the following viruses: rAAV-CaMKII-tdTom (control cells $\left.=\mathrm{GluN1}^{\mathrm{A} / \mathrm{fl}}\right)$, rAAV-CaMKII-CT100-T2A-tdTom (CT1 00 overexpression), rAAV-Syn-Cre-T2A-GFP (GluN1 deletion: $\mathrm{GluN1}^{--}$) and rAAV-Syn-Cre-T2A-GFP +

Table 1 mEPSC recordings of CT100-overexpressing DG granule cells

\begin{tabular}{|c|c|c|c|c|c|}
\hline \multicolumn{6}{|l|}{ Adult mice } \\
\hline $3 \mathrm{w}$ pi & \multicolumn{2}{|l|}{ Control $(n=22)$} & \multicolumn{3}{|l|}{ CT100 $(n=11)$} \\
\hline Frequency $[\mathrm{Hz}]$ & \multicolumn{2}{|l|}{$0.59[0.37-0.77]$} & \multicolumn{2}{|l|}{$0.48[0.44-0.71]$} & MW test: $p=0.9074$ \\
\hline 10w pi & \multicolumn{2}{|l|}{ Control $(n=40)$} & \multicolumn{2}{|l|}{ CT100 $(n=19)$} & \\
\hline Frequency [Hz] & \multicolumn{2}{|l|}{$0.71[0.4-0.92]$} & \multicolumn{2}{|l|}{$0.54[0.42-0.77]$} & MW test $p=0.21$ \\
\hline \multicolumn{6}{|l|}{ Young mice } \\
\hline $9 \mathrm{w}$ pi & \multicolumn{2}{|l|}{ Control $(n=56)$} & \multicolumn{2}{|l|}{ CT100 $(n=26)$} & \\
\hline Frequency $[\mathrm{Hz}]$ & \multicolumn{2}{|l|}{$0.81[0.51-1.02]$} & \multicolumn{2}{|l|}{$0.61[0.41-0.81]$} & MW test: $p=0.047$ \\
\hline GluN1 $1^{f / / f l} 9 w \mathrm{pi}$ & Control $(n=34)$ & CT100 $(n=10)$ & GluN1 $^{-/-}(n=21)$ & $\mathrm{GluN1}^{-/-}+\mathrm{CT} 100(\mathrm{n}=9)$ & \\
\hline Frequency $[\mathrm{Hz}]$ & $0.69[0.55-0.83]$ & $0.37[0.32-0.55]$ & $0.99[0.76-1.22]$ & $1.18[1.08-1.47]$ & $\begin{array}{l}\text { Kruskal-Wallis: } p<0.0001 ; \\
\text { Dunn's posttest: control } \\
\text { vs CT100 } p=0.04 ; \text { control } \\
\text { vs GluN1 } 1^{-1-} p=0.0045 ; \\
\text { GluN1 } 1^{-1-} \text { vs GluN1 } 1^{-1-}+\text { CT100 } \\
p=0.7895\end{array}$ \\
\hline Amplitude [pA] & $10.47[9.27-11.53]$ & $10.47[9.94-11.53]$ & 14.85 [12.96-16.09] & 12.4 [10.99-13.81] & $\begin{array}{l}\text { Kruskal-Wallis: } p<0.0001 ; \\
\text { Dunn's posttest: control } \\
\text { vs CT100 } p>0.9999 ; \text { control } \\
\text { vs GluN1 } 1^{-/-} p<0.0001 ; \\
\text { GluN1 }{ }^{-/-} \text {vs GluN1 } 1^{-1-}+\text { CT100 } \\
p=0.336\end{array}$ \\
\hline
\end{tabular}


Table 2 NMDAR-mediated currents in 5xFAD DG granule cells and virus-infected cells

\begin{tabular}{|c|c|c|c|}
\hline & Control $(n=16)$ & GluN1 $^{-/-}(n=15)$ & \\
\hline \multirow[t]{2}{*}{ NMDAR/AMPAR ratio } & $1 \pm 0.65$ & $0.13 \pm 0.04$ & MW test: $p<0.0001$ \\
\hline & WT $(n=22)$ & $5 \times \mathrm{xFA}(\mathrm{n}=29)$ & \\
\hline \multirow[t]{2}{*}{ NMDAR/AMPAR ratio } & $1.18[0.79-1.77]$ & $0.72[0.43-1.2]$ & MW test: $p=0.0029$ \\
\hline & WT $(n=18)$ & $5 \times F A D(n=25)$ & \\
\hline \multirow[t]{2}{*}{ Decay tau [ms] } & $62.91[57.75-67.48]$ & $66.51[59.2-72.86]$ & MW test: $p=0.0969$ \\
\hline & WT $(n=23)$ & $5 \times$ XAD $(n=22)$ & \\
\hline \multirow[t]{2}{*}{ Extrasynaptic amplitude [pA] } & $125.3[85.8-178.6]$ & $77.57[43.12-101.2]$ & MW test: $p=0.0003$ \\
\hline & WT $(n=23)$ & $5 x F A D(n=22)$ & \\
\hline Deactivation [ms] & 74.76 [63.62-88.33] & 79.43 [71.22-104.3] & MW test: $p=0.1712$ \\
\hline
\end{tabular}

rAAV-CaMKII-CT100-T2A-tdTom $\left(\mathrm{GluN1}^{-1-}\right.$ and CT100 overexpression) (Additional file 1: S1a). Nine weeks after rAAV injection, mEPSCs were recorded from infected DG granule cells. In accordance with the results shown above, mEPSC frequency was reduced in CT100 overexpressing DG granule cells (Additional file 3: S2c, blue bar). Furthermore, an increase in mEPSC frequency and amplitude was observed in $\mathrm{GluN1}^{-/-}$cells (red bar). Since deletion of GluN1 per se increased mEPSC frequency, we tested for an involvement of NMDARs in A $\beta$-toxicity by comparing $\mathrm{GluN1}^{-1-}$ cells with $\mathrm{CT} 100 / \mathrm{GluN}^{-1-}$ cells. Importantly, mEPSC frequency of CT100 expressing GluN1 ${ }^{-/-}$cells was not significantly different from the mEPSC frequency in $\mathrm{GluN1}^{-/-}$cells (Additional file 3: S2c, grey bar and Table 1). This indicates that NMDARs mediate the $A \beta$-induced reduction in the number of functional synapses. However, we cannot exclude that NMDARs and $\mathrm{A} \beta$ affect functional synapse number via independent parallel pathways. While performing electrophysiological recordings, neurons were filled with biocytin to subsequently perform morphological analysis. Interestingly, spine density was increased in dendrites of $A \beta$-overexpressing DG granule cells with no change in the distribution of stubby, thin and mushroom spines (Additional file 3: S2d, g, Tables 3 and 4). Thus, unexpectedly, A $\beta$ increased the number of spines while in parallel reducing the number of functional synapses.

\section{CT100(1716F) overexpression reduces the number of} functional synapses in adult mice

One intention of the study was to investigate the role of NMDARs for A $\beta$-toxicity in adult mice (12-16 weeks of age), i.e. at an age when the composition of NMDARs is similar to the composition in aging. However, CT100 overexpression was ineffective in adult mice (see above). We therefore generated a mutated version of CT100, in which isoleucine (I) at position 716 was exchanged to phenylalanine (F) (CT100(I716F)). This mutation alters the $\gamma$-secretase cleavage site and is known to increase the production of the toxic $A \beta_{42}[28,81]$. Expression of CT100(I716F) in primary hippocampal cultures increased $A \beta$ in the supernatant as verified by dot blot analysis (data not shown). Overexpression of CT100(I716F) induced a decrease in mEPSC frequency three weeks after rAAV injection into the DG of adult mice (Fig. 1e, h, k and Table 5). Thus, the increased production of $A \beta_{42}$ resulting from the I716F mutation indeed affected synaptic function stronger than the unmutated CT100. To investigate whether the reduction in $\mathrm{mEPSC}$ frequency results from a decreased release probability, we investigated the paired pulse ratio (PPR) of medial perforant path synapses. CT100(I716F) did not affect the PPR (Fig. 1n and Table 6). This indicates that $A \beta$ decreases mEPSC frequency by reducing synapse number or by increasing the number of synapses devoid of AMPAR (i.e silent synapses) [94]. Previous studies suggested that $A \beta$ alters neuronal excitability $[6,90]$. We therefore investigated intrinsic active and passive electrophysiological properties of DG granule cells (Additional file 4: S3). CT100(I716F) overexpression did not change threshold potential, action potential (AP) amplitude, duration, afterhyperpolarisation (AHP) and input resistance. Firing frequency, as well as early- and late adaptation were also not different between CT100(I716F) expressing DG granule cells and control cells (Additional file 4: S3b, c and Table 7). Thus, three-week

Table 3 Morphological analysis of CT100-overexpressing DG granule cells

\begin{tabular}{|c|c|c|c|c|c|}
\hline \multicolumn{6}{|l|}{ GluN1 ${ }^{f / f l} 9 w$ pi } \\
\hline Spine numbers & $\begin{array}{l}\text { Control } \\
(n=23)\end{array}$ & $\begin{array}{l}\text { CT100 } \\
(n=6)\end{array}$ & $\begin{array}{l}\mathrm{GluN1}^{-1-} \\
(\mathrm{n}=23)\end{array}$ & $\begin{array}{l}\text { GluN1 }^{-/-}+\text {CT100 } \\
(n=10)\end{array}$ & \\
\hline & 1.54 [1.25-1.84] & $2.22[1.95-2.37]$ & 1.73 [1.54-1.9] & $1.51[1.34-1.62]$ & $\begin{array}{l}\text { Kruskal-Wallis: } p=0.0015 \text {; Dunn's posttest: control } \\
\text { vs CT100 } p=0.0026 \text {; control vs GluN1 } 1^{-1} p=0.1332 \\
\text { GluN1 } 1^{--} \text {vs GluN1 } 1^{--}+C T 100 p=0.1119\end{array}$ \\
\hline
\end{tabular}




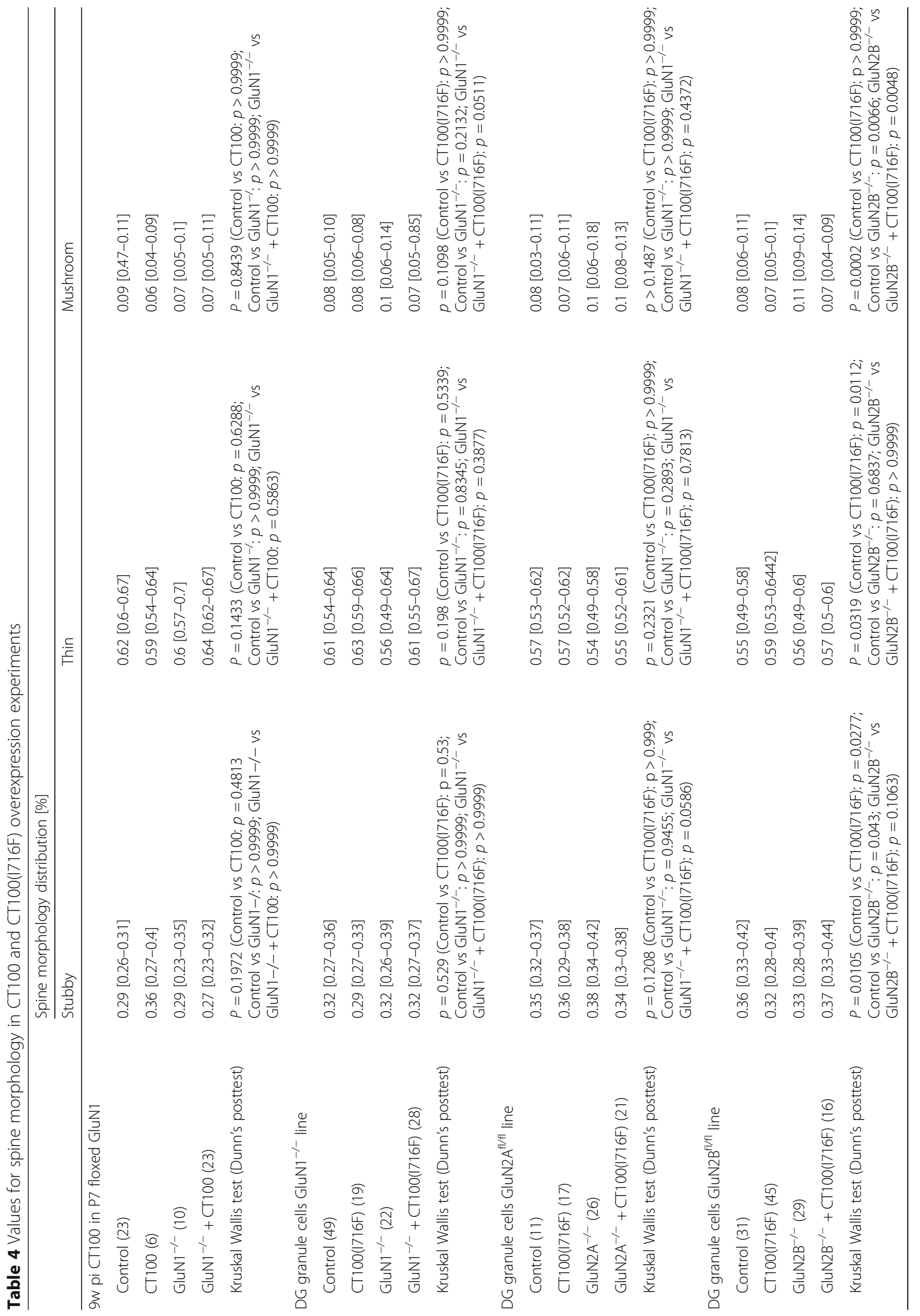




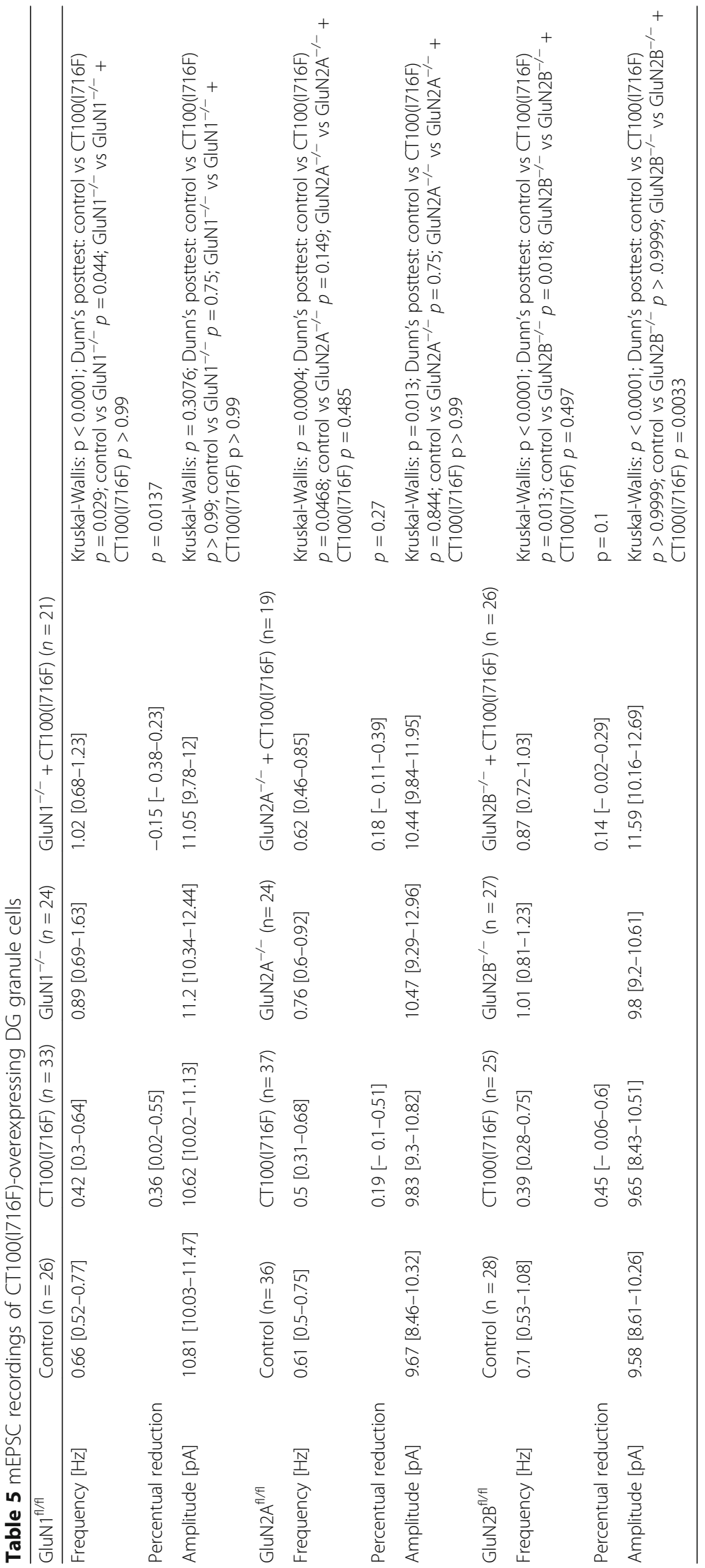


Table 6 Values of PPR of CT100(I716F)-overexpressing DG granule cells

\begin{tabular}{llll}
\hline & WT $(n=20)$ & $C T 100(1716 \mathrm{~F})(\mathrm{n}=20)$ & \\
\hline $25 \mathrm{~ms}$ ISI & $0.84[0.78-0.88]$ & $0.81[0.74-0.87]$ & MW-test: $p=0.2423$ \\
50 ms ISI & $1.1[1.05-1.17]$ & $1.13[1.07-1.26]$ & MW-test: $p=0.201$ \\
\hline
\end{tabular}

overproduction of $A \beta$ did not influence the active and passive properties of DG granule cells, but decreased the number of functional synapses.

\section{NMDARs are required for the $A \beta$-mediated reduction in functional synapse number in adult mice}

We next asked whether NMDARs are involved in the A $\beta$-mediated changes in synapse function in adult mice. To this end, mEPSCs were recorded in three different mouse strains, each with conditional deletion of either GluN1, GluN2A, or GluN2B (GluN1 ${ }^{\mathrm{t} / / \mathrm{fl}}$, GluN2A ${ }^{\mathrm{f} / \mathrm{fl}}$ and GluN2B ${ }^{\mathrm{A} /}$ $\mathrm{fl})$. Conditional deletion of the subunits has been induced by injection of either one or two viruses: rAAV-CaMKII-tdTom (control cells $=$ GluN1 $1^{\mathrm{f} / \mathrm{fl}}, \mathrm{GluN} \mathrm{A}^{\mathrm{f} / \mathrm{fl}}$ or GluN2B $\left.{ }^{\mathrm{f} / \mathrm{fl}}\right)$, rAAV-CaMKII-CT100(I716F)-T2A-tdTom (CT100(I716F) overexpression), rAAV-Syn-Cre-T2A-GFP $\left(\mathrm{GluN1}^{-/-}\right.$or GluN2A $\mathrm{A}^{-/-}$or GluN2B ${ }^{-/-}$granule cells) and rAAV-Syn-Cre-T2A-GFP + rAAV-CaMKII-CT100(I716F)-T2A-tdTom (NMDAR subunit deletion together with CT100(I716F) overexpression) (Fig. 1a). Synaptic currents were recorded three weeks after virus injection. CT100(I716F) overexpression significantly decreased mEPSC frequency by $20-45 \%$ without affecting mEPSC amplitude (Fig. 1e, h, k, Additional file 2: S4d, f, h and Table 5). Deletion of the GluN1 subunit as well as deletion of the GluN2B subunit increased mEPSC frequency (Fig. 1e, $\mathrm{n}$ and Table 5) similar to the observations in young mice. Importantly, overexpression of CT100(I716F) in $\mathrm{GluN1}^{-/-}, \mathrm{GluN}_{2} \mathrm{~A}^{-/-}$and
GluN2B $^{-/-}$granule cells did not significantly reduce mEPSC frequency (Fig. 1e, h, k and Table 5). Deletion of GluN1 abolished the effect of $A \beta$ overproduction almost completely: the CT100(I716F)-mediated mEPSC frequency reduction in $\mathrm{GluN1}^{-/-}$cells was significantly smaller than the reduction in wildtype cells (Fig. 1f). This indicates that the effect of $A \beta$ on the number of functional synapses is mediated via NMDARs (since there are nearly no functional NMDARs in $\mathrm{GluN1}^{-1-}$ cells; Additional file 2: S4b and Table 2). The deletion of only GluN2A or GluN2B had a smaller impact on the effect of CT100(I716F) on mEPSC frequency (Fig. 1i, l).

CT100(I716F) overexpression and NMDAR subunit knockout did not affect total length and arborisation of granule cell dendrites except for subtle changes in dendritic complexity in CT100(I716F) overexpressing cells compared to GluN2B ${ }^{-1-}$ cells (Fig. 2a, b, Additional file 5: S5 and Table 8). Interestingly, $A \beta$ overproduction via CT100(I716F) for 3 weeks did not influence the number of spines (Fig. 2c-f and Table 8) despite the A $\beta$-mediated reduction in functional synapse number (reduction in mEPSC frequency; Fig. 1e, h, k). This suggests that $A \beta$ increases the number of silent synapses. The deletion of the GluN1 or GluN2B subunit reduced spine number (Fig. 2d, $f$ and Table 8 ). Together with the increased mEPSC frequency (Fig. 1e, k), this indicates that deletion of GluN1 or GluN2B decreases silent synapse number. Spine morphology was not affected as shown by unaltered distributions of stubby, thin and mushroom spines in the GluN1 $1^{\mathrm{f} / \mathrm{fl}}$ and GluN2A ${ }^{\mathrm{f} / \mathrm{fl}}$ line, but small changes were observed in the GluN2B ${ }^{\mathrm{f} / \mathrm{fl}}$ line (Fig. 2g, i, j and Table 4).

NMDARs are not required for the spine loss in 5xFAD mice Our data so far showed that $A \beta$-overproduction for three weeks decreases the number of functional synapses and that NMDARs are required for this effect. There

Table 7 Intrinsic and firing properties of CT100(I716F) overexpressing DG granule cells

\begin{tabular}{|c|c|c|c|}
\hline & \multicolumn{3}{|l|}{ 3w pi CT100(1716F) } \\
\hline & Control & CT100(1716F) & \\
\hline & $n=31$ & $n=20$ & \\
\hline \multicolumn{4}{|l|}{ Passive properties } \\
\hline Input resistance $[\mathrm{m} \Omega]$ & $182[140-211.5]$ & 170 [129.5-184] & MW test: $p=0.2418$ \\
\hline \multicolumn{4}{|l|}{ Active properties } \\
\hline AP threshold [mV] & $-37.27[-39.18--33.78]$ & $-35.84[-39.04--30.2]$ & MW test: $p=0.5246$ \\
\hline AP width [ms] & $1.26[1.2-1.32]$ & $1.24[1.15-1.28]$ & MW test: $p=0.3286$ \\
\hline AP amplitude [mV] & $94.03[90.88-97.7]$ & 91.25 [87.12-95.74] & MW test: $p=0.1308$ \\
\hline $\mathrm{AHP}[\mathrm{mV}]$ & $-13.83[-16-58--10]$ & $-13.76[-15.77--11.23]$ & MW test: $p=0.7964$ \\
\hline \multicolumn{4}{|l|}{ Firing properties } \\
\hline Firing frequency $[\mathrm{Hz}]$ & 22 [16-26] & $20.5[17.25-23.75]$ & MW test: $p=0.7484$ \\
\hline Early adaptation [\%] & $451.7[356-563.4]$ & $391.4[347.1-543.1]$ & MW test: $p=0.6064$ \\
\hline Late adaptation [\%] & 41.98 [24.16-61.51] & 42.37 [20.43-102.4] & MW test: $p=0.8231$ \\
\hline
\end{tabular}



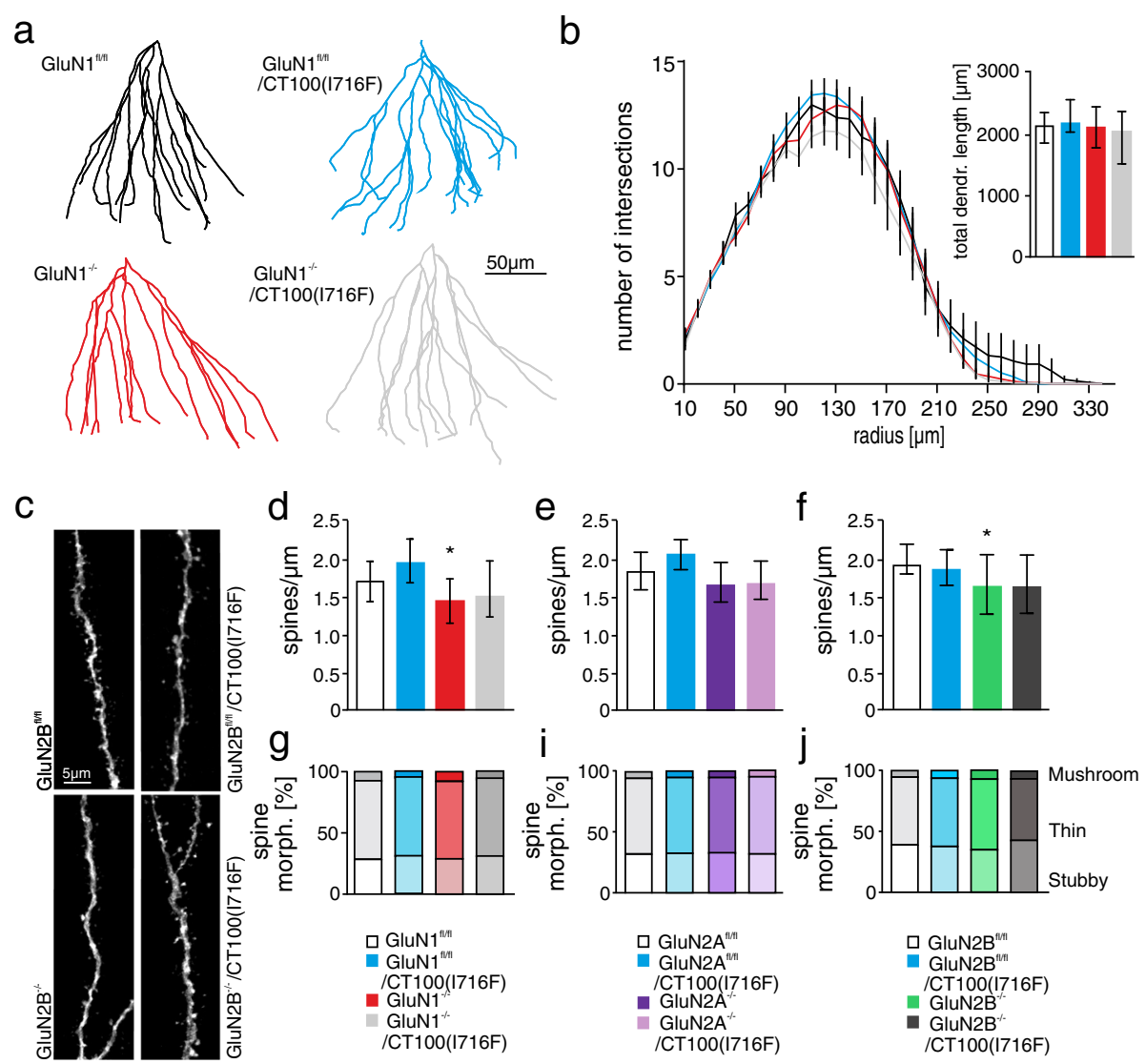

Fig. 2 CT100(1716F) overexpression does not affect morphology of granule cells in adult mice. a Examples of traced DG granule cells after biocytin filling. b Sholl analysis shows that neither CT100(1716F)-overexpression nor GluN1 knockout affects the number of intersections of granule cell dendrites. There is no difference in the total dendritic length of neurons in the different groups. c Examples of maximum intensity projections

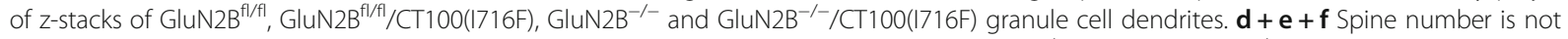
affected after three weeks of CT100(1716F)-overexpression. Spine number is reduced in GluN1 ${ }^{-/-}$(d), and GluN2B ${ }^{-/-}(\mathbf{f})$ granule cells. $\mathbf{g}+\mathbf{i}+\mathbf{j}$ The distribution of stubby, thin and mushroom spines is slightly affected by CT100(1716F)-overexpression and/or NMDAR subunit knockout with fewer

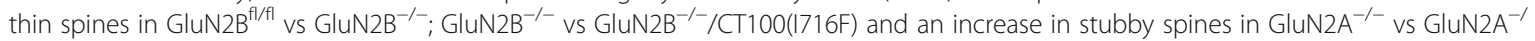

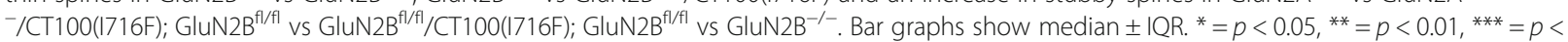
$0.001 ;$ morph. $=$ morphology

was no decrease in spine number, which, however, is an early event in $\mathrm{AD}$ pathogenesis that correlates well with cognitive impairment [84]. The absence of a spine loss in CT100(I716F)-expressing cells may be explained by the relatively short time-period of CT100(I716F) expression and perhaps by a moderate $A \beta$ overproduction using the virus-mediated approach. To analyze the role of NMDARs for A $\beta$-mediated spine loss, we thus employed 5xFAD mice, in which mutations in the APP and PSEN1 genes result in the accumulation of high levels of $A \beta_{42}$ [60]. In 12 months old 5xFAD mice, we detected $A \beta$ plaques throughout the DG in close proximity to the investigated cells (Fig. 3a). Spine density and spine morphology was not changed in granule cells of six-month-old 5xFAD mice (Additional file 6: S6d, e and Table 9). Consistently, there was no change in mEPSC frequency, but we found an increase in mEPSC amplitude (Additional file 6: S6g and Table 10). In contrast, spine density and mEPSC frequency were significantly reduced in granule cells of one-year-old 5xFAD mice (Fig. 3g, k, Tables 9 and 10). Spine density reduction in 5xFAD mice was not due to loss of a specific morphological spine subtype (Fig. $3 \mathrm{~m}$ and Table 11). Sholl analysis revealed no difference in dendritic arborization and total dendritic length between 5xFAD and WT mice (Fig. 3h, i and Table 9).

To investigate the role of NMDARs in $A \beta$-mediated synapse dysfunction and spine density reduction, $5 \mathrm{xFAD}$ mice were bred with conditional NMDAR $\mathrm{KO}$ lines $\left(\mathrm{GluN1} 1^{\mathrm{fl} / \mathrm{fl}}\right.$, GluN2A $\mathrm{A}^{\mathrm{fl} / \mathrm{fl}}$, and GluN2B $\mathrm{B}^{\mathrm{fl} / \mathrm{fl}}$ mice). Cre-recombinase expressing rAAVs were injected into the DG of nine-month old $5 \times \mathrm{xFA} / \mathrm{GluN} 1^{\mathrm{fl} / \mathrm{fl}}, 5 \mathrm{xFAD} / \mathrm{Glu}-$ $\mathrm{N} 2 \mathrm{~A}^{\mathrm{fl} / \mathrm{fl}}$ and $5 \mathrm{xFAD} / \mathrm{GluN} 2 \mathrm{~B}^{\mathrm{fl} / \mathrm{fl}}$ mice and littermate controls $\left(\mathrm{GluN1} 1^{\mathrm{f} / \mathrm{fl}}\right.$, GluN2A $\mathrm{A}^{\mathrm{f} / \mathrm{fl}}$ and GluN2B $\mathrm{B}^{\mathrm{f} / \mathrm{fl}}$ ) to induce 


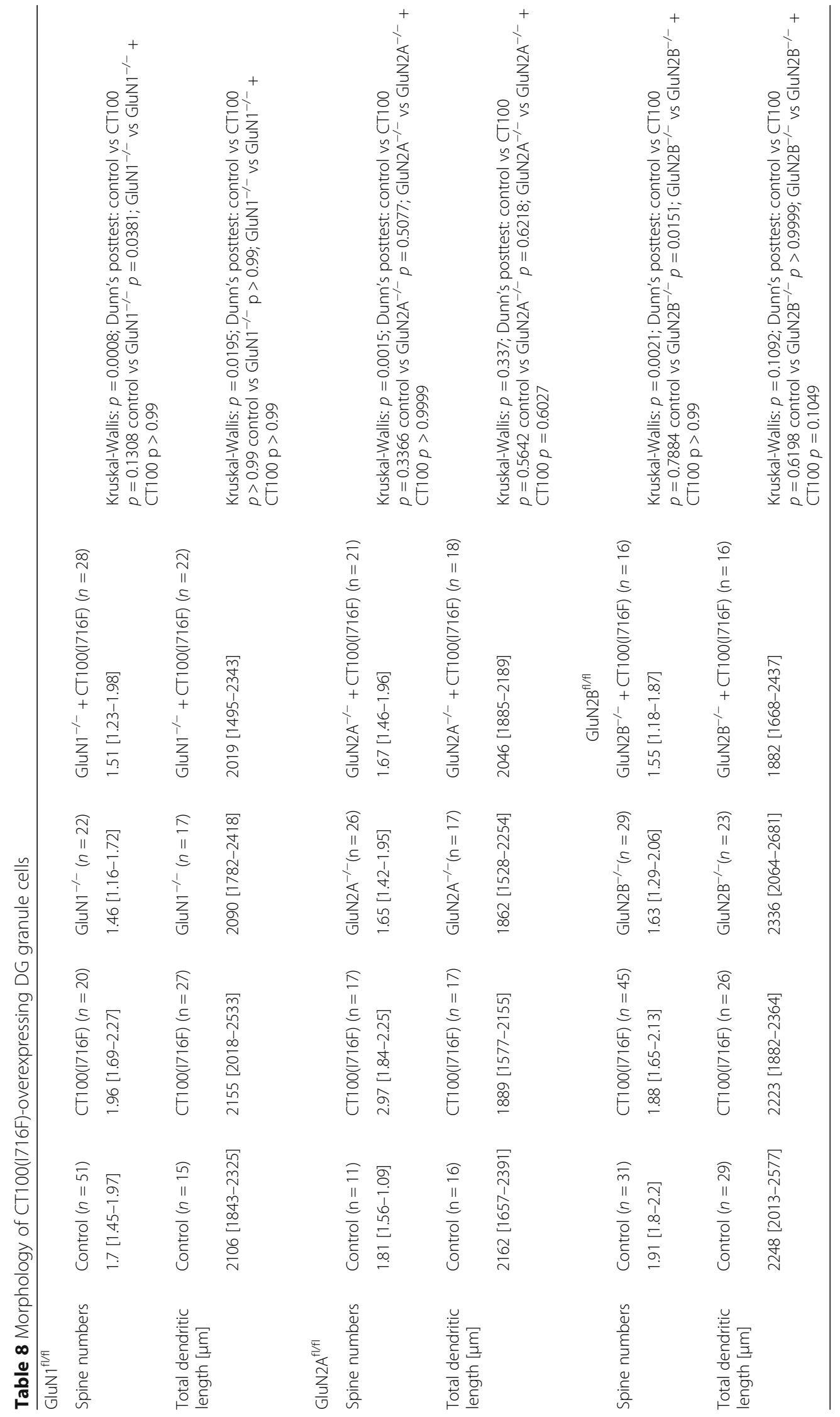




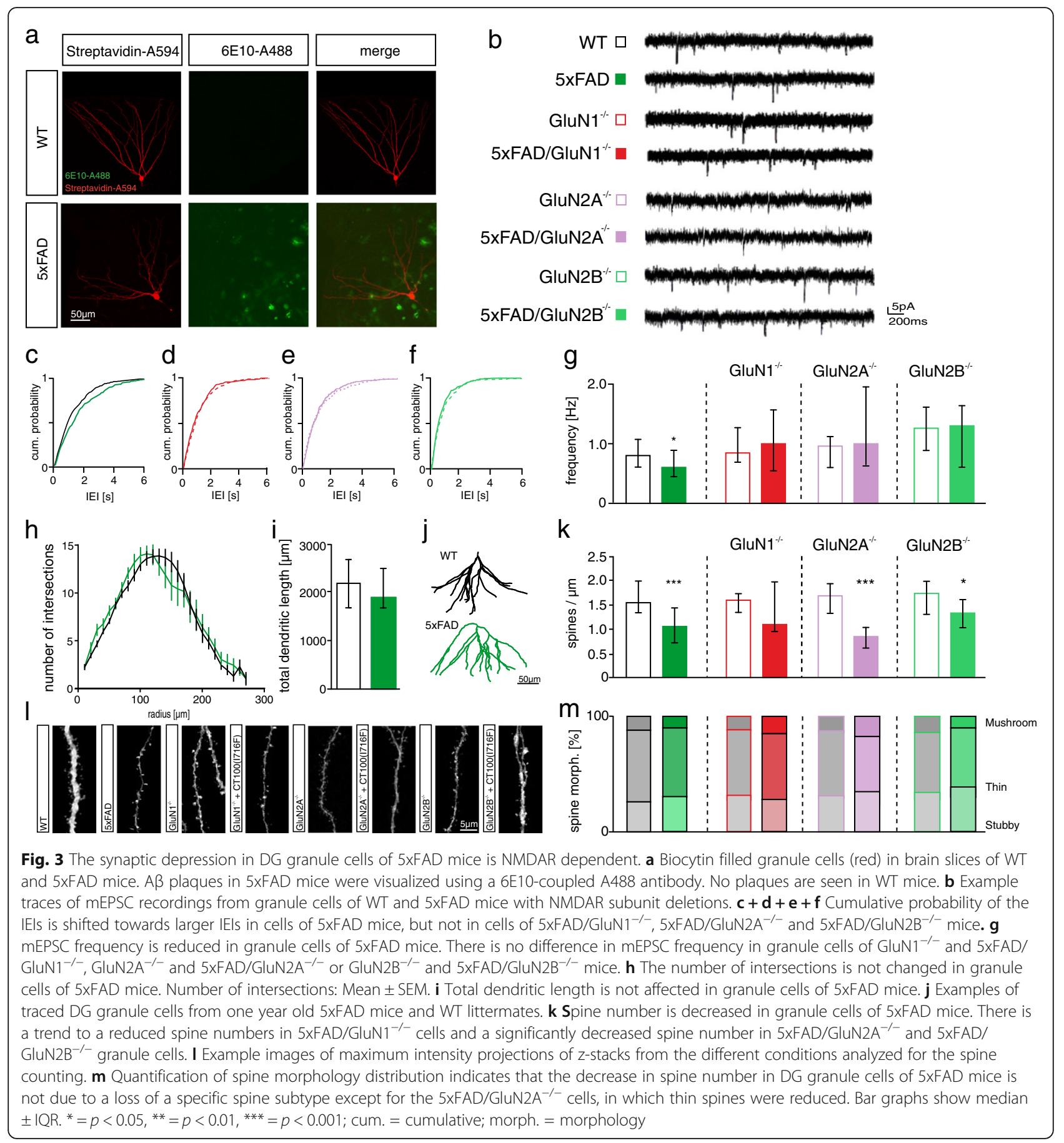

NMDAR subunit deletion $\left(\mathrm{GluN}^{-1-}, \mathrm{GluN}_{2} \mathrm{~A}^{-/-}\right.$and GluN2B $^{-/-}$cells). There was no difference in mEPSC frequency between $\mathrm{GluN1}^{-/-}$and $5 \mathrm{xFAD} / \mathrm{GluN1}^{-/-}$granule cells (Fig. 3g, red bars and Table 10). Similarly, the mEPSC frequency was not different between GluN2A $\mathrm{A}^{-/-}$and $5 \times \mathrm{xFD} / \mathrm{GluN} 2 \mathrm{~A}^{-/-}$granule cells as well as between $\mathrm{GluN}_{2} \mathrm{~B}^{-1-}$ and $5 \mathrm{xFAD} / \mathrm{GluN}^{-1} \mathrm{~B}^{-1-}$ granule cells (Fig. 3g, light green bars and Table 10). Thus, NMDARs are required for the reduction in the number of functional synapses in paradigms with short-time (with CT100(I716F) expression for three weeks) and chronic $\mathrm{A} \beta$-overproduction (in 5xFAD mice). In fact, the protection that was induced by NMDAR subunit deletion was more evident in 5xFAD mice than in cells with CT100(I716F) expression. In addition, the deletion of only one subunit (GluN2A or GluN2B) was sufficient to abolish the influence of $A \beta$ on functional synapse number in $5 x F A D$ mice. 
Table 9 Morphological analysis of the 5xFAD mouse model

\begin{tabular}{|c|c|c|c|}
\hline \multicolumn{4}{|l|}{$6 \mathrm{~m} \mathrm{DG}$} \\
\hline \multirow[t]{2}{*}{ Spine numbers } & WT $(n=17)$ & $5 \times$ XAD $(n=20)$ & \\
\hline & $1.25[0.93-1.56]$ & $1.36[1-1.6]$ & MW-test: $p=0.8923$ \\
\hline \multirow[t]{2}{*}{ Total dendritic length } & WT $(n=13)$ & $5 \times F A D(n=20)$ & \\
\hline & 2707 [2131-3003] & 2425 [2134-2630] & MW-test: $p=0.1275$ \\
\hline \multicolumn{4}{|l|}{ 1a DG } \\
\hline \multirow[t]{8}{*}{ Spine numbers } & $W T(n=27)$ & $5 \times F A D(n=28)$ & \\
\hline & 1.54 [1.35-1.99] & $1.07[0.73-1.46]$ & MW-test: $p<0.0001$ \\
\hline & $\mathrm{GluN1}^{-1-}(n=6)$ & $5 \times \mathrm{XAD} / \mathrm{GluN1}^{-/-}(n=12)$ & \\
\hline & $1.62[1.36-1.76]$ & $1.13[0.96-2.02]$ & MW-test: $p=0.325$ \\
\hline & GluN2A ${ }^{-1-}(n=12)$ & $5 \times$ FAD/GluN2A ${ }^{-1-}(n=10)$ & \\
\hline & $1.7[1.36-1.98]$ & $0.87[0.64-1.04]$ & MW-test: $p=0.0001$ \\
\hline & GluN2B $^{-1-}(n=28)$ & $5 \times$ FAD/GluN2B ${ }^{-1-}(n=13)$ & \\
\hline & 1.73 [1.29-1.96] & $1.33[1.02-1.6]$ & MW-test: $p=0.0165$ \\
\hline \multirow[t]{2}{*}{ Total dendritic length $[\mu \mathrm{m}]$} & WT $(n=22)$ & $5 \times F A D(n=19)$ & \\
\hline & 2222 [1704-2660] & 1882 [1708-2480] & MW-test: $p=0.4763$ \\
\hline
\end{tabular}

Knockout of GluN1, GluN2A or GluN2B per se did not affect spine density of granule cells. Importantly, deletion of GluN2A or GluN2B did not prevent the reduction in spine number in dendrites of granule cells in 5xFAD mice (Fig. 3k, light green bars and Table 9). The highly variable spine number in $5 \times \mathrm{FAD} / \mathrm{GluN1}^{-/-}$cells reduces the informative value of the non-significant difference to the spine number in $\mathrm{GluN1}^{-/-}$cells (Fig. 3k, red bars and Table 9). This hampers conclusions about the role of GluN1. However, the strong trend to reduced spine numbers in $5 \mathrm{xFAD} / \mathrm{GluN}^{-/-}$cells indicates that NMDARs play a small role in the $A \beta$-mediated spine number reduction, in contrast to their requirement for the $A \beta$-mediated changes in functional synapse number.

\section{$A \beta$ decreases surface expression of NMDARs}

Results from the experiments described above showed that NDMARs are involved in $A \beta$-mediated changes of synapse function in adult mice. However, changes in the expression of NMDARs altered the number of functional

Table 10 mEPSC recordings from the 5xFAD mouse model

\begin{tabular}{|c|c|c|c|}
\hline \multicolumn{4}{|l|}{$6 \mathrm{~m} \mathrm{DG}$} \\
\hline & $W T(n=24)$ & $5 \times F A D(n=23)$ & \\
\hline Frequency [Hz] & $0.73[0.44-0.91]$ & $0.66[0.45-1.2]$ & MW-test: $p=0.6612$ \\
\hline Amplitude [pA] & $10.08[9.15-10.52]$ & $10.64[10.15-11.7]$ & MW-test: $p=0.0013$ \\
\hline \multicolumn{4}{|l|}{ 1a DG } \\
\hline & $W T(n=27)$ & $5 x F A D(n=21)$ & \\
\hline Frequency [Hz] & $0.80[0.61-1.07]$ & $0.61[0.44-0.89]$ & MW-test: $p=0.026$ \\
\hline \multirow[t]{2}{*}{ Amplitude [pA] } & $10.44[8.54-11.95]$ & $11.2[8.94-11.86]$ & MW-test: $p=0.47$ \\
\hline & GluN1 $^{-1-}(n=17)$ & $5 \times \mathrm{xFA} / \mathrm{GluN1} 1^{-/-}(\mathrm{n}=17)$ & \\
\hline Frequency [Hz] & $0.85[0.68-1.26]$ & $1.02[0.55-1.56]$ & MW-test: $p=0.8119$ \\
\hline \multirow[t]{2}{*}{ Amplitude [pA] } & $11.2[10.24-12.84]$ & $10.43[9.66-12.31]$ & MW-test: $p=0.394$ \\
\hline & GluN2A $^{-1-}(n=23)$ & $5 \times$ xAD/ GluN2A ${ }^{-1-}(n=17)$ & \\
\hline Frequency [Hz] & $0.97[0.61-1.13]$ & $1.01[0.64-1.98]$ & MW-test: $p=0.2802$ \\
\hline \multirow[t]{2}{*}{ Amplitude [pA] } & 9.0 [8.38-9.93] & $9.45[8.97-10.72]$ & MW-test: $p=0.1626$ \\
\hline & GluN2B $^{-/-}(n=21)$ & $5 \times$ FAD/ GluN2B ${ }^{-/-}(n=16)$ & \\
\hline Frequency $[\mathrm{Hz}]$ & $1.26[0.89-1.61]$ & $1.31[0.6-1.63]$ & MW-test: $p>0.999$ \\
\hline Amplitude [pA] & 11.63 [10.72-12.14] & 10.06 [9.88-12.92] & MW-test: $p=0.3232$ \\
\hline
\end{tabular}


Table 11 Overview of values for spine morphology in 5xFAD mice

\begin{tabular}{|c|c|c|c|}
\hline & \multicolumn{3}{|c|}{ Spine Morphology distribution [\%] } \\
\hline & Stubby & Thin & Mushroom \\
\hline \multicolumn{4}{|l|}{$6 \mathrm{~m}$ 5xFAD DG } \\
\hline WT (17) & $0.31[0.25-0.34]$ & $0.6[0.56-0.64]$ & $0.1[0.06-0.1]$ \\
\hline $5 x F A D(18)$ & $0.32[0.27-0.35]$ & $0.58[0.56-0.61]$ & $0.1[0.09-0.11]$ \\
\hline Mann-Whitney test & $p=0.4$ & $p=0.142$ & $p=0.85$ \\
\hline \multicolumn{4}{|l|}{ 1a 5xFAD DG } \\
\hline WT (29) & $0.26[0.22-0.35]$ & $0.64[0.6-0.7]$ & $0.08[0.04-0.11]$ \\
\hline 5xFAD (28) & $0.32[0.23-0.38]$ & $0.59[0.23-0.38]$ & $0.09[0.06-0.16]$ \\
\hline Mann-Whitney test & $p=0.32$ & $p=0.13$ & $p=0.14$ \\
\hline GluN1 ${ }^{-/-}(7)$ & $0.32[0.27-0.39]$ & $0.56[0.45-0.62]$ & $0.12[0.12-0.16]$ \\
\hline $5 \times \mathrm{FAD} / \mathrm{GluN} 21^{-/-}(12)$ & $0.29[0.25-0.31]$ & $0.57[0.47-0.63]$ & $0.14[0.12-0.21]$ \\
\hline Mann-Whitney test & $p=0.16$ & $p=0.526$ & $p=0.29$ \\
\hline GluN2A $^{-/-}(12)$ & $0.31[0.24-0.36]$ & $0.58[0.47-0.64]$ & $0.13[0.09-0.17]$ \\
\hline $5 \times \mathrm{xAD} / \mathrm{GluN2 \textrm {A } ^ { - 1 - }}(10)$ & $0.39[0.32-0.5]$ & $0.39[0.29-0.46]$ & $0.19[0.14-0.26]$ \\
\hline Mann-Whitney test & $p=0.02$ & $p=0.002$ & $p=0.025$ \\
\hline GluN2B $^{-/-}(15)$ & $0.35[0.27-0.4]$ & $0.53[0.45-0.62]$ & $0.1[0.08-0.14]$ \\
\hline $5 \times \mathrm{FAD} / \mathrm{GluN} 2 \mathrm{~B}^{-/-}(11)$ & $0.42[0.34-0.52]$ & $0.47[0.37-0.54]$ & $0.13[0.1-0.16]$ \\
\hline Mann-Whitney test & $p=0.0362$ & $p=0.0687$ & $p=0.3565$ \\
\hline
\end{tabular}

synapses also in control mice. Thus, an important question is if $A \beta$ reduces the number of functional synapses by influencing the surface expression of NMDARs. To address this question, we investigated synaptic and extrasynaptic NMDAR-mediated currents in granule cells of one-year-old 5xFAD mice. The NMDAR/AMPAR ratio was reduced in $5 x F A D$ mice when compared to that in WT littermates (Fig. 4a, b and Table 2). This suggests that the number of synaptic NMDARs is markedly reduced in one-year-old 5xFAD mice considering the reduction in frequency of AMPAR-mediated mEPSCs (Fig. 3g). The gating kinetics of NMDARs depend on their subunit composition. For example, the deactivation time-constant of GluN1/GluN2A-containing NMDARs is 14 times smaller than that of GluN1/GluN2B-containing NMDARs [86]. Consequently, the deactivation time-constant of triheteromeric GluN1/GluN2A/GluN2B-containining NMDARs is with $78.7 \mathrm{~ms}$ in between that of the diheteromeric NMDARs [86]. Decay time constant of synaptic NMDAR-mediated currents was unaltered in one-year-old 5xFAD mice (Fig. 4c, d and Table 2). As the decay time constant of synaptic NMDAR-mediated currents is mainly determined by the deactivation time constant, this result suggests that the subunit composition of synaptic NMDARs was not changed in 5xFAD mice. It has been shown that extrasynaptic NMDARs play an important role for mediating neuron dysfunction and cell death in various brain diseases that are connected to over-activation of NMDARs (for review see [62]). We studied extrasynaptic NMDAR-mediated currents by ultra-fast application of glutamate onto nucleated patches of granule cells from one-year-old 5xFAD and WT mice. The amplitude of extrasynaptic NMDAR-mediated currents was decreased in $5 x F A D$ mice (Fig. 4e, $\mathrm{f}$ and Table 2 ), showing that $\mathrm{A} \beta$ overexpression reduces also the number of extrasynaptic NMDARs. The deactivation time constant was not changed in granule cells of 5xFAD mice (Fig. $4 \mathrm{~g}, \mathrm{~h}$ and Table 2), indicating that the subunit composition of extrasynaptic NMDARs is not affected by $A \beta$-overproduction.

\section{Discussion}

The open-channel NMDAR blocker Memantine has been shown to improve cognitive abilities in moderate-to-severe $\mathrm{AD}$ patients $[68,100]$. A series of studies using rodent neurons additionally suggested that NMDARs are involved in the pathophysiology of $\mathrm{AD}[74,79]$. Importantly, there is evidence that NMDARs mediate $A \beta$-induced changes in synaptic function and neuronal morphology [45, 70, 74, 99]. However, conclusions about the role of NMDARs in A $\beta$-toxicity were mostly drawn from studies using cultured neurons, which are relatively immature, and mostly by using pharmacological tools. Thus, these studies do not allow drawing unequivocal conclusions about the contribution of NMDAR subunits to A $\beta$ toxicity.

We show in this study that NMDARs are required for the $A \beta$-induced reduction of functional synapse number in adult mice. Thus, deletion of either subunit was sufficient to protect granule cells from loss of functional synapses in 5XFAD mice. Interestingly, deletion of GluN2A was effective in 1 year old 5XFAD mice, but 


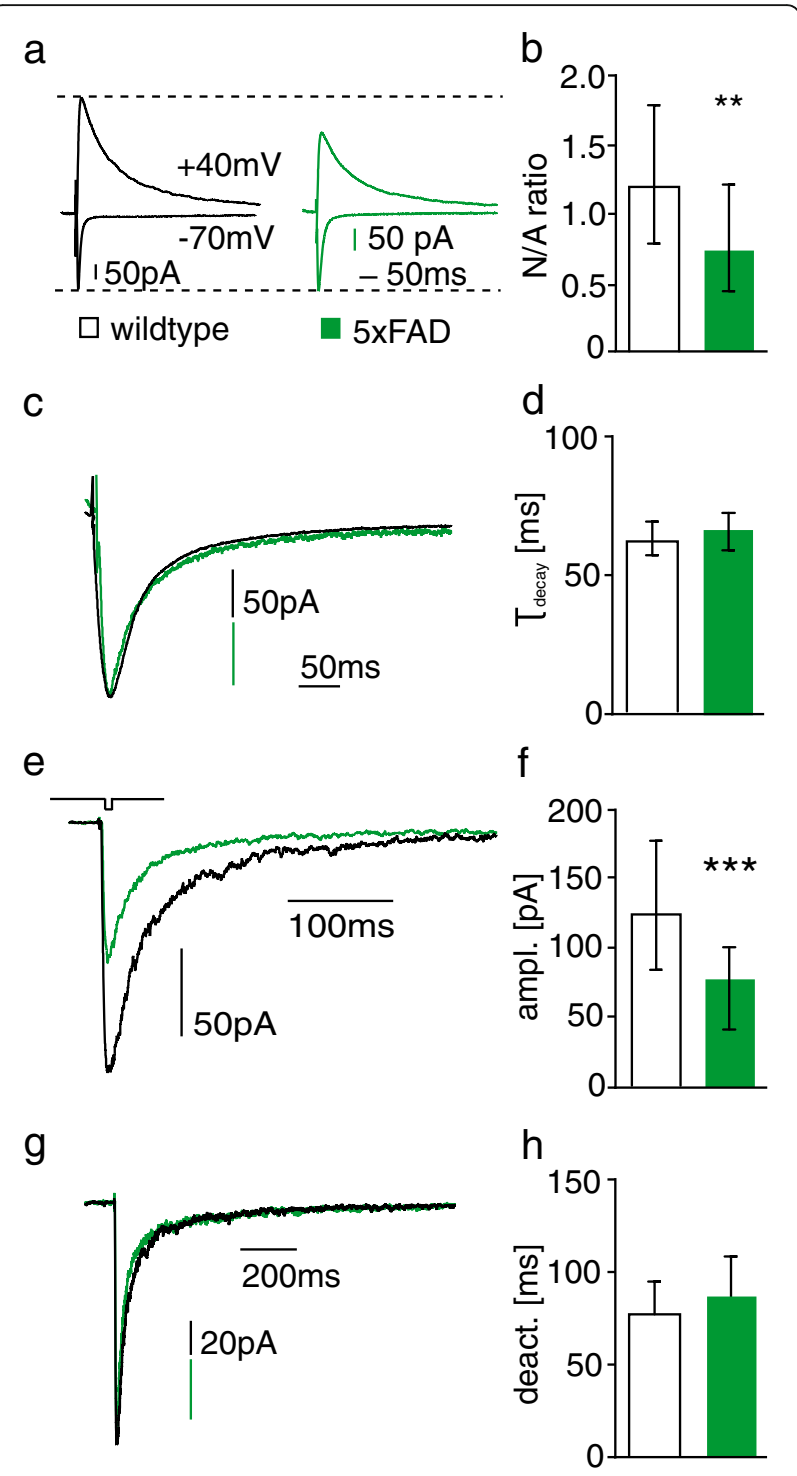

Fig. 4 The amplitude of synaptic and extrasynaptic NMDARmediated currents is reduced in 5XFAD mice. a Example traces of NMDAR- and AMPAR-mediated currents recorded at holding potential of $-70 \mathrm{mV}$ and $+40 \mathrm{mV}$, respectively, in DG granule cells of $\mathrm{WT}$ and $5 \times F A D$ mice. $\mathbf{b}$ The NMDAR/AMPAR (N/A) ratio is significantly reduced in DG granule cells of $5 \times F A D$ mice. $\mathbf{c}$ Example traces of NMDAR-mediated currents recorded at $-30 \mathrm{mV}$. $\mathbf{d}$ The time constant of decay currents is not different between WT and 5xFAD cells. e Example traces of extrasynaptic NMDAR-mediated currents evoked by ultrafast-application of glutamate onto nucleated patches. f The peak amplitude of NMDAR-mediated currents is significantly reduced in granule cells of 5XFAD mice. $\mathbf{g}$ Example traces of normalized extrasynaptic NMDAR-mediated currents. $\mathbf{h}$ There is no difference in the deactivation time constant between DG granule cells of WT and 5XFAD mice. Bar graphs show median \pm IQR.

${ }^{*}=p<0.05,{ }^{* *}=p<0.01,{ }^{* * *}=p<0.001$, ampl. = amplitude, deact. $=$ deactivation did not prevent reduction of functional synapse number in CT100(I716F)-expressing cells of 4-5 months old mice. Perhaps the role of GluN2A for $A \beta$ toxicity was different between 4 and 5 months and 1 year old mice because of an aging dependent upregulation of GluN2A. Age dependent changes in subunit expression may also explain why previous studies had shown that block of NMDARs with non-selective or GluN2B-specific antagonists, but not GluN2A-preferring antagonists prevent the $A \beta$-mediated depression of synaptic current amplitudes in organotypic slice cultures [37].

Virus-mediated deletion of NMDARs per se increases the number of functional synapses in DG granule cells as evidenced by the increase in mEPSC frequency. This was most pronounced in cells with deletion of the GluN2B subunit for three months. This is in line with previous studies on the influence of NMDARs on functional synapse number of cortical, CA1 and CA3 neurons $[1,19,22,96]$ and suggests that the GluN2B-mediated reduction of functional synapse number is a widespread homeostatic plasticity mechanism that controls the strength of neuronal communication in different neuron types. The underlying mechanism for the increase in the number of functional synapses is most likely an NMDAR-mediated $\mathrm{Ca}^{2+}$-influx, which activates intracellular signaling molecules such as such as PKA and CaMKII leading to an upregulation of AMPAR number on the cell surface and in synapses [32, 76]. GluN2B-containing NMDARs are not only involved in the homeostatic control of functional synapse number, but also in the activity-dependent long-term plasticity of synaptic strength in mature neurons. Thus, genetic deletion of the GluN2B subunit reduces synaptic LTP [93]. Interestingly, GluN2B-containing NMDARs are required for the $A \beta$-induced reduction of synaptic long-term potentiation [70].

Our experiments with adult $5 \times$ FAD mice showed that GluN2A and GluN2B are dispensable for the A $\beta$-induced spine reduction. This is in line with some studies showing that block of GluN2B-containing NMDARs does not prevent $A \beta$-mediated spine loss $[23,82]$, but contrasts the finding of others that the GluN2B subunit mediates spines loss [82]. However, a general role of NMDARs in $A \beta$-induced spine reduction was found in other studies [4, $66,74,99]$. Differences in in the maturity of neurons may well account for the contrasting findings of these studies and our study. NMDARs contributed to the $A \beta$-induced spine reduction in immature cultured neurons (studies mentioned above), but not in the brain of adult mice as shown in our study. The impact of NMDARs on neuron morphology in general may decrease with development. The morphology of immature cultured neurons is more flexible and spine stability lower than in mature neurons of the adult brain, suggesting that the mechanisms that control neuron morphology and spine density may well differ between immature and mature neurons. Indeed, 
block of NMDARs with APV for 14 days decreases spine density in cultured neurons [10]. Genetic deletion of the GluN2B subunit during developmental stages at which the rate of changes in neuron morphology is still high results in reduced spine number and alterations in dendrite arborization of CA1, CA3 and DG granule cells $[2,15,17$, 19]. Similarly, we observed a lower number of spines three weeks after deletion of the GluN2B subunit in 3-4 months old mice. However, after chronic GluN2B deletion for three months in one year old mice this effect vanished. This may indicate that the influence of GluN2B decreases with brain age or alternatively that the absence of GluN2B function for longer a time-period is compensated by other mechanisms that influence spine density such as BDNF-signaling $[46,69]$, or activation of voltage-gated-Ca-channels [80].

Differences in the spine stability may also explain that $A \beta$ overproduction for three weeks with a virus-mediated approach did not reduce spine density in adult mice (this study), but decreased spine density in organotypic slice cultures already after 2-7 days [30, 99]. However, there are several other possible differences between young and adult brains that may account for the age-dependent decrease in $A \beta$-toxicity, such as differences in virus-infection efficacy or $A \beta$-expression levels in infected neurons. The bigger effect of $A \beta$ overproduction on spine density or synaptic function in some studies using organotypic slices of young mice than in our study with adult mice may also be explained by the different types of viruses that were used. Thus, $A \beta$ overproduction may be more pronounced when using Sindbis viruses [37, 99] than when using rAAVs (this study) for CT100 overexpression. In addition, the mode of application determines extent and velocity of $A \beta$-toxicity. Thus, repeated $A \beta$-application into the DG of 1 -year-old mice over 6 days is neurotoxic [5]. It is likely that peak $A \beta$ concentration is higher in this approach than in brains with 10-weeks virus-mediated CT100 overexpression or in 6 months-old $5 \mathrm{xFAD}$ mice. We did observe a spine number reduction in granule cells of 12-months old 5xFAD mice. Again, the mechanisms that reduce spine number may differ between the direct application of high doses of $A ß$ and the more chronic $A \beta$ overproduction in 5xFAD mice, which might better resemble the pathological situation in the brain of AD patients. Differences in the mechanisms of $A \beta$-toxicity between immature and mature neurons and/or high and lower $A \beta$-concentration could explain that GluN2B-containing NMDARs are required for the $A \beta$-mediated spine reduction in cultured neurons [30, 75, 99], but not in 5xFAD mice. In conclusion, other studies and our findings suggest that pathophysiological mechanisms of $A \beta$-toxicity change with brain maturation. Of note, a possible higher $A \beta$-toxicity in immature than in adult brains is not at odds with the fact that $\mathrm{AD}$ is a disease of elderly people. Thus, $\mathrm{A} \beta$ concentration may increase with age. In addition, chronically elevated $A \beta$ levels may be necessary to induce toxicity leading to AD.

Our results so far lead to the question: What is the possible link of $A \beta$ and NMDARs? $A \beta$ may alter NMDAR activity by different mechanisms: 1 . direct interaction with NMDARs [11], 2. increased ambient glutamate levels (due to reduced glutamate reuptake) [45], or by changes in NMDAR expression [79]. Direct binding of Aß to or next to NMDARs influences their function of localization [13, 40]. For example, $\mathrm{A} ß$ has been shown to directly activate recombinant GluN2A- and GluN2B-containing NMDARs expressed in Xenopus oocytes [85]. An augmented and potentially toxic calcium influx may be the consequence from the direct $A \beta$ with NMDAR interaction or increased ambient glutamate levels [3]. Interestingly, this effect is subunit-dependent in cultured cortical neurons: Activation of GluN2B-containing NMDARs elevates, whereas activation of GluN2A-containing NMDARs reduces intracellular calcium levels upon stimulation with $A ß[16]$. Interestingly, there is also evidence that activation of NMDARs by $A ß$ may not require ion-flux via the channel pore suggesting a metabotropic function of NMDARs when activated by $A ß[4,37]$. There are several proposed mechanisms by which $A \beta$ may affect the expression of NMDARs on the cell surface. For example, $A \beta$ reduces the expression of synaptic NMDARs in cultured neurons and $\mathrm{Tg} 2576$ mice possibly by activation of $\alpha-7$ nicotinic receptors, which promotes receptor internalization in a PP2B and STEP-dependent fashion [38, 79]. Another mechanism may be the $A \beta$-mediated depletion of EphB2, which has been shown to reduce surface expression of NMDARs on DG granule cells [9]. Consistently, the current amplitude of synaptic NMDAR-mediated currents is reduced in DG granule cells of adult 5xFAD mice (this study) and CA1 neurons in organotypic slices that were infected with CT100-expressing viruses [37]. In contrast to the study of Kessels and colleagues, in which CT100 reduced preferentially the current amplitude of GluN2B-containing NMDARs, we did not find any indication for changes in the subunit composition [37, 67]. This difference may be well explained by a smaller contribution of GluN2B-containing NMDARs to synaptic currents in mature neurons than in immature neurons of organotypic slices. It has been hypothesized that the reduction in synaptic NMDAR number results not only from increased receptor internalization, but also from redistribution from synaptic to extrasynaptic sites [79]. A redistribution of NMDARs may contribute to A $\beta$-toxicity as the activation of synaptic NMDARs is thought to stimulate pro-survival signaling in neurons, whereas that of extrasynaptic NMDARs induces neuron apoptosis [25, 44], but see also: [101]. In fact, a redistribution of NMDARs is thought to play a role for the pathophysiology of another neurodegenerative disease, e.g. in Huntington's disease. Thus, exposure of neurons to huntingtin decreases the expression 
of synaptic NMDARs $[53,61]$ and increases the expression of extrasynaptic GluN2B-containing NMDARs [53]. We analyzed currents mediated by extrasynaptic NMDARs to investigate if a similar receptor redistribution is also involved in $\mathrm{AD}$. Interestingly, we observed a reduction in the amplitude of extrasynaptic NMDAR-mediated currents again without indication for changes in the subunit composition. This rules out that the toxic influence of $A \beta$ results from a redistribution of NMDARs from synaptic to extrasynaptic sites or from a change in the composition of extrasynaptic NMDARs with a relative increase in GluN2B-containing NMDARs. In fact, the decay time constant of synaptic NMDAR-mediated currents was in a similar range to the time constant of extrasynaptic NMDAR-mediated currents (62 ms and $76 \mathrm{~ms}$, respectively), suggesting that the composition of synaptic and extrasynaptic NMDARs is very similar.

Our observation that synaptic and extrasynaptic NMDAR-mediated current amplitudes reduced to a similar extent without changes in subunit composition is in accordance with findings from a post-mortem study of the brain of human $\mathrm{AD}$ patients and healthy controls. In this study the authors revealed a comparable downregulation of the GluN2A and GluN2B subunit in hippocampus, temporal and cingulate cortex [34]. However, other studies were indicative for a downregulation in the expression of preferentially GluN2B-containing NMDARs in the hippocampus of $\mathrm{AD}$ patients [54]. The fact that we did not observe changes in spine number three months after genetic deletion of the GluN2B and GluN1 subunit makes it is unlikely that the downregulation of synaptic or extrasynaptic NMDARs is responsible for the A $\beta$-mediated reduction in functional synapses and spine number. It is rather the activation of the remaining NMDARs that contributes to the $A \beta$-mediated changes in functional synapse number and NMDAR-independent mechanisms that mediate the spine loss of granule cells in adult mice. The NMDAR downregulation may therefore even reduce the effect of $A \beta$ on functional synapse number.

\section{Conclusion}

Using conditional NMDAR subunit KO mice, we showed that NMDARs are required for the influence of $A \beta$ on the number of functional synapses of dentate gyrus granule cells. However, they were not responsible for the reduction in spine number that are observed after chronic $A \beta$-overproduction. Similar observations were made in somatosensory neurons (data not shown), indicating that the role of NMDARs in A $\beta$-toxicity is not specific for the dentate gyrus. Our data suggest that pharmacological block of NMDARs may reduce the influence of $A \beta$ on synaptic function at early $\mathrm{AD}$ stages, but most likely does not prevent the changes in neuron morphology that are seen at later AD stages. This could also explain why the low affinity NMDAR antagonist Memantine alleviates cognitive symptoms to some extent, but does not halt or reverse the progression of $\mathrm{AD}[20,48]$.

\section{Additional files}

\begin{abstract}
Additional file 1: S1. AAV-CT100 overexpression leads to synaptic depression in young mice. a pAAV constructs used for control conditions (tdTomato) and for stable co-expression of a fluorescent marker and CT100 (tdTomato) or Crerecombinase (GFP). $\mathbf{b}$ Example traces of $m$ EPSC recordings from adult and young control or CT100-overexpressing DG granule cells. c + d CT100 overexpression for 9 weeks does not reduce mEPSC frequency and does not change the cumulative propability of inter-event-intervals (IEIs) in DG granule cells from adult mice. $\mathbf{e}+\mathbf{f} C T 100$ overexpression for 9 weeks reduces mEPSC frequency in DG granule cells from younger mice (injected at P7). Bar graphs show median \pm IQR. ${ }^{*}=p<0.05,{ }^{* *}=p<0.01,{ }^{* * *}=p<0.001$ (PDF $1550 \mathrm{~kb}$ )
\end{abstract}

Additional file 2: S4. NMDAR subunit deletion does not influence mEPSC peak amplitude in DG granule cells. a Example traces of NMDAR/ AMPAR (N/A) ratio recordings three weeks after injection of AAV-Cre-T2AGFP. $\mathbf{b}$ N/A ratio is strongly reduced three weeks after NMDAR deletion $\left(\mathrm{GluN1}^{-/-}\right)$in comparison to cells injected with a control virus (AAV-T2A$\left.\mathrm{tdTom}=\mathrm{GluN1} 1^{\mathrm{fl} / \mathrm{fl}}\right)$. c-h CT100(I716F) overexpression does not influence peak amplitude (blue bars). Peak amplitude is increased in GluN2B ${ }^{-1-}$ compared to GluN2B ${ }^{-/-} / C T 100(1716 F)$ DG granule cells. Bar graphs show median \pm IQR . ${ }^{*}=p<0.05,{ }^{* *}=p<0.01,{ }^{* * *}=p<0.001$, norm. = normalized, cum. = cumulative, ampl. = amplitude (PDF $1391 \mathrm{~kb})$

Additional file 3: S2. Synaptic depression induced by $\subset 100$ overexpression is NMDAR dependent in young mice. a Example traces of mEPSC recordings from mice injected with AAV-Tom (GluN1 $\left.{ }^{\mathrm{f} / \mathrm{fl}}\right)$, AAV-CT100-T2A-Tom (GluN1 $1^{\mathrm{f} / \mathrm{f} /}$ CT100), AAV-Cre-T2A-GFP (GluN1 ${ }^{-1}$ ) or co-injected with AAV-CT100-T2A-Tom and AAV-Cre-T2A-GFP (GluN1 $\left.{ }^{-/} / \mathrm{CT} 100\right)$. b Cumulative probability of inter-eventinterval (IEI) is shifted to longer IEls in CT100(I716F) overexpressing cells. c mEPSC frequency is reduced in CT100-overexpressing and increased in $\mathrm{GluN1}^{-/}$DG granule cells. There is no difference between $\mathrm{GluN1}^{-/-}$cells and $\mathrm{GluN1}^{-/-} / \mathrm{CT} 100$ DG granule cells. $\mathbf{e}+\mathbf{f}$ Peak amplitude is increased in $\mathrm{GluN1}^{-/}$cells compared to $\mathrm{GluN1} 1^{\mathrm{f} / \mathrm{fl}}$ cells. Cumulative probability of the amplitude is shifted towards larger amplitues in $\mathrm{GluN1}^{-/}$neuons. $\mathbf{d}$ CT100 increased the spine number of DG granule cells from slices of young mice. $\mathbf{g}$ The quantification of the spine morphology distribution shows no significant difference between the groups. Bar graphs show median $\pm \mathrm{IQR} .{ }^{*}=p<0.05,{ }^{* *}=p<0.01,{ }^{* * *}=p<0.001$; cum. $=$ cumulative; morph. $=$ morphology (PDF $1485 \mathrm{~kb})$

Additional file 4: S3. Active and passive properties of DG granule cells are not altered by $C 1100(1716 \mathrm{~F})$ overexpression. a Example traces of action potentials (APs) from control and CT100(1716F)-overexpressing DG granule cells. $\mathbf{b}$ CT100(1716F) overexpression does not alter the intrinsic properties threshold, amplitude, half-amplitude (HA) duration, afterhyperpolarization (AHP) and input resistance of DG granule cells compared to control cells. c Firing frequency, earlyand late adaptation do not differ between control and CT100(1716F)-overexpressing DG granule cells. $\mathbf{d}$ Example traces of firing patterns of control and CT100(I716F) DG granule cells. Bar graphs show median \pm IQR. (PDF 146 kb)

Additional file 5: S5. CT100(I716F) overexpression does not influence total dendritic length in adult mice. a Examples of traced DG granule cells of the GluN2A ${ }^{f / f l}$ mouse line. $\mathbf{b}$ The number of intersections analyzed by Sholl analysis is not changed by $C T 100(1716 \mathrm{~F})$ overexpression, GluN2A subunit deletion and GluN2A deletion in combination with $\mathrm{CT100(1716F)}$ overexpression. Mean \pm SEM. Total dendritic length is not different between the groups. c Examples of traced DG granule cells of the GluN2B $B^{\mathrm{fl} / \mathrm{ll}}$ mouse line. $\mathbf{d}$ Sholl analysis of the number of intersections shows subtle changes in dendritic complexity in GluN2B ${ }^{-\prime}$ -/CT100(I716F) cells compared to their respective control (GluN2B ${ }^{-/-}$). Mean \pm SEM. Total dendritic length is not different between the groups. Bar graphs show median \pm IQR.; dendr. = dendritic, morph. = morphology (PDF 133 kb)

Additional file 6: S6. Functional and structural properties are not affected in six-month old 5xFAD mice. a Examples of traced DG granule cells of sixmonth old WT and 5xFAD mice. $\mathbf{b}$ The number of intersections per radius is not changed as revealed by a Sholl analysis of cells from 5xFAD and WT mice. Mean \pm SEM. $\mathbf{c}$ Total dendritic length is also not changed. $\mathbf{d}+\mathbf{e}$ Spine number and spine morphology is not affected in DG granule cells of 5xFAD compared to WT mice. $\mathbf{f}$ mEPSC example traces of WT and 5xFAD granule 
cells. $\mathbf{g} \mathbf{+} \mathbf{h}$ mEPSC frequency is not changed in 5 XFAD compared to WT granule cells, but peak amplitude is increased. Bar graphs show median \pm IQR. ${ }^{*}=p<0.05,{ }^{* *}=p<0.01,{ }^{* * *}=p<0.001 ;$ dendr. = dendritic, morph. $=$ morphology (PDF $100 \mathrm{~kb}$ )

Additional file 7: Table S1. mEPSC recordings of CT100-overexpressing DG granule cells. Table S2. Morphological analysis of $\mathrm{CT}$ 100-overexpressing DG granule cells. Table S3. mEPSC recordings of CT100(1716F)-overexpressing DG granule cells. Table S4. Morphology of CT100(1716F)-overexpressing DG granule cells. Table S5. Values of PPR of CT100(1716F)-overexpressing DG granule cells. Table S6. mEPSC recordings from the 5XFAD mouse model. Table S7. Morphological analysis of the 5xFAD mouse model. Table S8. Intrinsic and firing properties of CT100(1716F) overexpressing DG granule cells. Table S9. NMDAR-mediated currents in 5xFAD DG granule cells and virusinfected cells. Table S10. Values for spine morphology in CT100 and CT100(1716F) overexpression experiments. Table S11. Overview of values for spine morphology in 5xFAD mice. (DOCX $49 \mathrm{~kb}$ )

\section{Abbreviations}

ACSF: Artificial cerebral spine fluid; AD: Alzheimer Disease; AHP: Afterhyperpolarisation; AMPAR: a-amino-3-hydroxy-5-methyl-4isoxazolepropionic acid receptor; AP: Action potential; AB: Amyloid Beta; CT100: C-terminal 100; DG: Dentate gyrus; LTP: Long-term-potentiation; mEPSC: miniature excitatory post-synaptic current; NMDA/AMPA ratio: NMDAR-mediated to AMPAR-mediated current amplitude ratio; NMDARs: N-methyl-D-aspartate receptors; PPR: Paired-pulse ratio; rAAVs: Recombinant adeno-associated viruses; SD: Standard deviation

\section{Acknowledgements}

We thank Benjamin Schieb, Barbara Biesalski and Dr. Viola Nordström for technical help. We further thank the Light Microscopy Facility of the DKFZ Heidelberg for support with confocal imaging.

\section{Funding}

The work was supported by a grant from the Fritz Thyssen foundation to JVE (Az. 10.15.1.017MN) and a NIH grant to RM (NIH grant AG032132).

\section{Availability of data and materials}

The datasets analyzed during the current study are available from the corresponding authors upon reasonable request. All original tables are also available for download as Additional file 7.

\section{Authors' contributions}

MKM, EJ performed experiments. MKM, EJ and JvE analyzed and interpreted the results. MKM and EJ performed statistical analysis. MKM, EJ, RM, and JVE designed the study. MKM, EJ, KS, RM, and JvE wrote the manuscript and approved the final manuscript

\section{Ethical approval}

All applicable international, national, and institutional guidelines for care and use of animals were followed. This article does not contain studies with human participants.

\section{Competing interests}

The authors declare that they have no conflict of interest.

\section{Publisher's Note}

Springer Nature remains neutral with regard to jurisdictional claims in published maps and institutional affiliations.

\section{Author details}

'Institute of Pathophysiology, University Medical Center of the Johannes Gutenberg University Mainz, 55128 Mainz, Germany. ${ }^{2}$ Synaptic Signalling and Neurodegeneration, German Center for Neurodegenerative Diseases (DZNE), 53127 Bonn, Germany. ${ }^{3}$ Department of Cellular Neurobiology, Brain Research Institute, Niigata University, Niigata 951-8585, Japan. ${ }^{4}$ Center for Neural Circuits and Behavior, Department of Neuroscience and Section for Neurobiology, Division of Biology, University of California at San Diego, San Diego, CA, USA.
Received: 28 September 2018 Accepted: 29 September 2018 Published online: 23 October 2018

\section{References}

1. Adesnik $\mathrm{H}$ et al (2008) NMDA receptors inhibit synapse unsilencing during brain development. Proc Natl Acad Sci U S A 105(14):5597-5602

2. Akashi K et al (2009) NMDA receptor GluN2B (GluR epsilon 2/NR2B) subunit is crucial for channel function, postsynaptic macromolecular organization, and actin cytoskeleton at hippocampal CA3 synapses. J Neurosci 29(35): 10869-10882

3. Alberdi E et al (2010) Amyloid beta oligomers induce Ca2+ dysregulation and neuronal death through activation of ionotropic glutamate receptors. Cell Calcium 47(3):264-272

4. Birnbaum JH et al (2015) Calcium flux-independent NMDA receptor activity is required for Abeta oligomer-induced synaptic loss. Cell Death Dis 6:e1791

5. Brouillette J et al (2012) Neurotoxicity and memory deficits induced by soluble low-molecular-weight amyloid-beta1-42 oligomers are revealed in vivo by using a novel animal model. J Neurosci 32(23):7852-7861

6. Busche MA et al (2012) Critical role of soluble amyloid-beta for early hippocampal hyperactivity in a mouse model of Alzheimer's disease. Proc Natl Acad Sci U S A 109(22):8740-8745

7. Calabrese B et al (2007) Rapid, concurrent alterations in pre- and postsynaptic structure induced by naturally-secreted amyloid-beta protein. Mol Cell Neurosci 35(2):183-193

8. Chen $\mathrm{Q}$ et al (2007) Differential roles of NR2A- and NR2B-containing NMDA receptors in activity-dependent brain-derived neurotrophic factor gene regulation and limbic epileptogenesis. J Neurosci 27(3):542-552

9. Cisse $M$ et al (2011) Reversing EphB2 depletion rescues cognitive functions in Alzheimer model. Nature 469(7328):47-52

10. Collin C, Miyaguchi K, Segal M (1997) Dendritic spine density and LTP induction in cultured hippocampal slices. J Neurophysiol 77(3):1614-1623

11. Cousins SL et al (2009) Amyloid precursor protein 695 associates with assembled NR2A- and NR2B-containing NMDA receptors to result in the enhancement of their cell surface delivery. J Neurochem 111(6):1501-1513

12. Cull-Candy S, Brickley S, Farrant M (2001) NMDA receptor subunits: diversity, development and disease. Curr Opin Neurobiol 11(3):327-335

13. De Felice FG et al (2007) Abeta oligomers induce neuronal oxidative stress through an N-methyl-D-aspartate receptor-dependent mechanism that is blocked by the Alzheimer drug memantine. J Biol Chem 282(15):1159011601

14. Domingues A et al (2007) Toxicity of beta-amyloid in HEK293 cells expressing NR1/NR2A or NR1/NR2B N-methyl-D-aspartate receptor subunits. Neurochem Int 50(6):872-880

15. Espinosa JS et al (2009) Uncoupling dendrite growth and patterning: singlecell knockout analysis of NMDA receptor 2B. Neuron 62(2):205-217

16. Ferreira IL et al (2012) Amyloid beta peptide 1-42 disturbs intracellular calcium homeostasis through activation of GluN2B-containing N-methyl-daspartate receptors in cortical cultures. Cell Calcium 51(2):95-106

17. Gambrill AC, Barria A (2011) NMDA receptor subunit composition controls synaptogenesis and synapse stabilization. Proc Natl Acad Sci U S A 108(14): $5855-5860$

18. Gladding CM, Raymond LA (2011) Mechanisms underlying NMDA receptor synaptic/extrasynaptic distribution and function. Mol Cell Neurosci 48(4): 308-320

19. Gray JA et al (2011) Distinct modes of AMPA receptor suppression at developing synapses by GluN2A and GluN2B: single-cell NMDA receptor subunit deletion in vivo. Neuron 71(6):1085-1101

20. Grossberg GT (2005) Rationalizing therapeutic approaches in Alzheimer's disease. CNS Spectr 10(11 Suppl 18):17-21

21. Guardia-Laguarta C et al (2010) Clinical, neuropathologic, and biochemical profile of the amyloid precursor protein I716F mutation. J Neuropathol Exp Neurol 69(1):53-59

22. Hall BJ, Ripley B, Ghosh A (2007) NR2B signaling regulates the development of synaptic AMPA receptor current. J Neurosci 27(49):13446-13456

23. Hanson JE et al (2014) Chronic GluN2B antagonism disrupts behavior in wildtype mice without protecting against synapse loss or memory impairment in Alzheimer's disease mouse models. J Neurosci 34(24):8277-8288

24. Hardingham GE, Bading H (2010) Synaptic versus extrasynaptic NMDA receptor signalling: implications for neurodegenerative disorders. Nat Rev Neurosci 11(10):682-696 
25. Hardingham GE, Fukunaga Y, Bading H (2002) Extrasynaptic NMDARs oppose synaptic NMDARs by triggering CREB shut-off and cell death pathways. Nat Neurosci 5(5):405-414

26. Hardy J, Selkoe DJ (2002) The amyloid hypothesis of Alzheimer's disease: progress and problems on the road to therapeutics. Science 297(5580):353-356

27. Harris AZ, Pettit DL (2007) Extrasynaptic and synaptic NMDA receptors form stable and uniform pools in rat hippocampal slices. J Physiol 584(Pt 2):509519

28. Herl $L$ et al (2009) Mutations in amyloid precursor protein affect its interactions with presenilin/gamma-secretase. Mol Cell Neurosci 41(2):166174

29. Hsia AY et al (1999) Plaque-independent disruption of neural circuits in Alzheimer's disease mouse models. Proc Natl Acad Sci U S A 96(6):32283233

30. Hsieh $\mathrm{H}$ et al (2006) AMPAR removal underlies Abeta-induced synaptic depression and dendritic spine loss. Neuron 52(5):831-843

31. Hu NW et al (2009) GluN2B subunit-containing NMDA receptor antagonists prevent Abeta-mediated synaptic plasticity disruption in vivo. Proc Natl Acad Sci U S A 106(48):20504-20509

32. Husi H, Grant SG (2001) Isolation of 2000-kDa complexes of N-methyl-Daspartate receptor and postsynaptic density 95 from mouse brain. J Neurochem 77(1):281-291

33. Hynd MR, Scott HL, Dodd PR (2001) Glutamate(NMDA) receptor NR1 subunit mRNA expression in Alzheimer's disease. J Neurochem 78(1):175182

34. Hynd MR, Scott HL, Dodd PR (2004) Differential expression of N-methyl-Daspartate receptor NR2 isoforms in Alzheimer's disease. J Neurochem 90(4): 913-919

35. Jacob CP et al (2007) Alterations in expression of glutamatergic transporters and receptors in sporadic Alzheimer's disease. J Alzheimers Dis 11(1):97-116

36. Kamenetz $\mathrm{F}$ et al (2003) APP processing and synaptic function. Neuron 37(6):925-937

37. Kessels HW, Nabavi S, Malinow R (2013) Metabotropic NMDA receptor function is required for beta-amyloid-induced synaptic depression. Proc Natl Acad Sci U S A 110(10):4033-4038

38. Kurup P et al (2010) Abeta-mediated NMDA receptor endocytosis in Alzheimer's disease involves ubiquitination of the tyrosine phosphatase STEP61. J Neurosci 30(17):5948-5957

39. Kutsuwada T et al (1992) Molecular diversity of the NMDA receptor channel. Nature 358(6381):36-41

40. Lacor PN et al (2007) Abeta oligomer-induced aberrations in synapse composition, shape, and density provide a molecular basis for loss of connectivity in Alzheimer's disease. J Neurosci 27(4):796-807

41. Lambert MP et al (1998) Diffusible, nonfibrillar ligands derived from Abeta142 are potent central nervous system neurotoxins. Proc Natl Acad Sci U S A 95(11):6448-6453

42. Lau CG, Zukin RS (2007) NMDA receptor trafficking in synaptic plasticity and neuropsychiatric disorders. Nat Rev Neurosci 8(6):413-426

43. Le WD et al (1995) Cell death induced by beta-amyloid 1-40 in MES 23.5 hybrid clone: the role of nitric oxide and NMDA-gated channel activation leading to apoptosis. Brain Res 686(1):49-60

44. Leveille $\mathrm{F}$ et al (2008) Neuronal viability is controlled by a functional relation between synaptic and extrasynaptic NMDA receptors. FASEB J 22(12):42584271

45. Li S et al (2009) Soluble oligomers of amyloid Beta protein facilitate hippocampal long-term depression by disrupting neuronal glutamate uptake. Neuron 62(6):788-801

46. Lin B et al (2005) Theta stimulation polymerizes actin in dendritic spines of hippocampus. J Neurosci 25(8):2062-2069

47. Liu Y et al (2007) NMDA receptor subunits have differential roles in mediating excitotoxic neuronal death both in vitro and in vivo. J Neurosci 27(11):2846-2857

48. Lopez OL et al (2009) Long-term effects of the concomitant use of memantine with cholinesterase inhibition in Alzheimer disease. J Neurol Neurosurg Psychiatry 80(6):600-607

49. Lue LF et al (1999) Soluble amyloid beta peptide concentration as a predictor of synaptic change in Alzheimer's disease. Am J Pathol 155(3): 853-862

50. Luo J et al (1997) The majority of N-methyl-D-aspartate receptor complexes in adult rat cerebral cortex contain at least three different subunits (NR1/ NR2A/NR2B). Mol Pharmacol 51(1):79-86
51. Masliah E et al (1994) Synaptic and neuritic alterations during the progression of Alzheimer's disease. Neurosci Lett 174(1):67-72

52. McLean CA et al (1999) Soluble pool of Abeta amyloid as a determinant of severity of neurodegeneration in Alzheimer's disease. Ann Neurol 46(6):860866

53. Milnerwood AJ et al (2010) Early increase in extrasynaptic NMDA receptor signaling and expression contributes to phenotype onset in Huntington's disease mice. Neuron 65(2):178-190

54. Mishizen-Eberz AJ et al (2004) Biochemical and molecular studies of NMDA receptor subunits NR1/2A/2B in hippocampal subregions throughout progression of Alzheimer's disease pathology. Neurobiol Dis 15(1):80-92

55. Mizuta I et al (1998) Developmental expression of NMDA receptor subunits and the emergence of glutamate neurotoxicity in primary cultures of murine cerebral cortical neurons. Cell Mol Life Sci 54(7):721-725

56. Monyer $\mathrm{H}$ et al (1992) Heteromeric NMDA receptors: molecular and functional distinction of subtypes. Science 256(5060):1217-1221

57. Monyer $\mathrm{H}$ et al (1994) Developmental and regional expression in the rat brain and functional properties of four NMDA receptors. Neuron 12(3):529540

58. Naslund J et al (2000) Correlation between elevated levels of amyloid betapeptide in the brain and cognitive decline. JAMA 283(12):1571-1577

59. Niewoehner B et al (2007) Impaired spatial working memory but spared spatial reference memory following functional loss of NMDA receptors in the dentate gyrus. Eur J Neurosci 25(3):837-846

60. Oakley $\mathrm{H}$ et al (2006) Intraneuronal beta-amyloid aggregates, neurodegeneration, and neuron loss in transgenic mice with five familial Alzheimer's disease mutations: potential factors in amyloid plaque formation. J Neurosci 26(40):10129-10140

61. Okamoto $S$ et al (2009) Balance between synaptic versus extrasynaptic NMDA receptor activity influences inclusions and neurotoxicity of mutant huntingtin. Nat Med 15(12):1407-1413

62. Parsons MP, Raymond LA (2014) Extrasynaptic NMDA receptor involvement in central nervous system disorders. Neuron 82(2):279-293

63. Petralia RS et al (2010) Organization of NMDA receptors at extrasynaptic locations. Neuroscience 167(1):68-87

64. Rammes $\mathrm{G}$ et al (2011) Therapeutic significance of NR2B-containing NMDA receptors and mGluR5 metabotropic glutamate receptors in mediating the synaptotoxic effects of beta-amyloid oligomers on long-term potentiation (LTP) in murine hippocampal slices. Neuropharmacology 60(6):982-990

65. Rammes $\mathrm{G}$ et al (2017) Involvement of GluN2B subunit containing Nmethyl-d-aspartate (NMDA) receptors in mediating the acute and chronic synaptotoxic effects of oligomeric amyloid-beta (Abeta) in murine models of Alzheimer's disease (AD). Neuropharmacology 123:100-115

66. Rammes $\mathrm{G}$ et al (2018) The NMDA receptor antagonist Radiprodil reverses the synaptotoxic effects of different amyloid-beta (Abeta) species on longterm potentiation (LTP). Neuropharmacology 140:184-192

67. Reinders NR et al (2016) Amyloid-beta effects on synapses and memory require AMPA receptor subunit GluA3. Proc Natl Acad Sci U S A 113(42): E6526-E6534

68. Reisberg B et al (2003) Memantine in moderate-to-severe Alzheimer's disease. N Engl J Med 348(14):1333-1341

69. Rex CS et al (2007) Brain-derived neurotrophic factor promotes long-term potentiation-related cytoskeletal changes in adult hippocampus. J Neurosci 27(11):3017-3029

70. Ronicke $\mathrm{R}$ et al (2011) Early neuronal dysfunction by amyloid beta oligomers depends on activation of NR2B-containing NMDA receptors. Neurobiol Aging 32(12):2219-2228

71. Rumbaugh G, Vicini S (1999) Distinct synaptic and extrasynaptic NMDA receptors in developing cerebellar granule neurons. J Neurosci 19(24): 10603-10610

72. Sandhu FA et al (1993) NMDA and AMPA receptors in transgenic mice expressing human beta-amyloid protein. J Neurochem 61(6):2286-2289

73. Schneider LS et al (2011) Lack of evidence for the efficacy of memantine in mild Alzheimer disease. Arch Neurol 68(8):991-998

74. Shankar GM et al (2007) Natural oligomers of the Alzheimer amyloid-beta protein induce reversible synapse loss by modulating an NMDA-type glutamate receptor-dependent signaling pathway. J Neurosci 27(11):28662875

75. Shankar GM et al (2008) Amyloid-beta protein dimers isolated directly from Alzheimer's brains impair synaptic plasticity and memory. Nat Med 14(8): 837-842 
76. Sheng M (2001) The postsynaptic NMDA-receptor--PSD-95 signaling complex in excitatory synapses of the brain. J Cell Sci 114(Pt 7):1251

77. Sheng M et al (1994) Changing subunit composition of heteromeric NMDA receptors during development of rat cortex. Nature 368(6467):144-147

78. Sinor JD et al (2000) NMDA and glutamate evoke excitotoxicity at distinct cellular locations in rat cortical neurons in vitro. J Neurosci 20(23):8831-8837

79. Snyder EM et al (2005) Regulation of NMDA receptor trafficking by amyloidbeta. Nat Neurosci 8(8):1051-1058

80. Stanika RI, Flucher BE, Obermair GJ (2015) Regulation of postsynaptic stability by the L-type Calcium Channel CaV1.3 and its interaction with PDZ proteins. Curr Mol Pharmacol 8(1):95-101

81. Suarez-Calvet M et al (2014) Autosomal-dominant Alzheimer's disease mutations at the same codon of amyloid precursor protein differentially alter Abeta production. J Neurochem 128(2):330-339

82. Tackenberg $C$ et al (2013) NMDA receptor subunit composition determines beta-amyloid-induced neurodegeneration and synaptic loss. Cell Death Dis 4:e608

83. Tariot PN et al (2004) Memantine treatment in patients with moderate to severe Alzheimer disease already receiving donepezil: a randomized controlled trial. JAMA 291(3):317-324

84. Terry RD et al (1991) Physical basis of cognitive alterations in Alzheimer's disease: synapse loss is the major correlate of cognitive impairment. Ann Neurol 30(4):572-580

85. Texido $L$ et al (2011) Amyloid beta peptide oligomers directly activate NMDA receptors. Cell Calcium 49(3):184-190

86. Tovar KR, McGinley MJ, Westbrook GL (2013) Triheteromeric NMDA receptors at hippocampal synapses. J Neurosci 33(21):9150-9160

87. Tovar KR, Westbrook GL (1999) The incorporation of NMDA receptors with a distinct subunit composition at nascent hippocampal synapses in vitro. $J$ Neurosci 19(10):4180-4188

88. Traynelis SF et al (2010) Glutamate receptor ion channels: structure, regulation, and function. Pharmacol Rev 62(3):405-496

89. Tu W et al (2010) DAPK1 interaction with NMDA receptor NR2B subunits mediates brain damage in stroke. Cell 140(2):222-234

90. Varga $\mathrm{E}$ et al (2014) Abeta(1-42) enhances neuronal excitability in the CA1 via NR2B subunit-containing NMDA receptors. Neural Plast 2014:584314

91. Vicini S et al (1998) Functional and pharmacological differences between recombinant N-methyl-D-aspartate receptors. J Neurophysiol 79(2):555-566

92. von Engelhardt J et al (2007) Excitotoxicity in vitro by NR2A- and NR2Bcontaining NMDA receptors. Neuropharmacology 53(1):10-17

93. von Engelhardt J et al (2008) Contribution of hippocampal and extrahippocampal NR2B-containing NMDA receptors to performance on spatial learning tasks. Neuron 60(5):846-860

94. Voronin LL, Cherubini E (2004) 'Deaf, mute and whispering' silent synapses: their role in synaptic plasticity. J Physiol 557(Pt 1):3-12

95. Walsh DM et al (2005) The role of cell-derived oligomers of Abeta in Alzheimer's disease and avenues for therapeutic intervention. Biochem Soc Trans 33(Pt 5):1087-1090

96. Wang CC et al (2011) A critical role for GluN2B-containing NMDA receptors in cortical development and function. Neuron 72(5):789-805

97. Wang J et al (1999) The levels of soluble versus insoluble brain Abeta distinguish Alzheimer's disease from normal and pathologic aging. Exp Neurol 158(2):328-337

98. Watanabe $\mathrm{M}$ et al (1992) Developmental changes in distribution of NMDA receptor channel subunit mRNAs. Neuroreport 3(12):1138-1140

99. Wei W et al (2010) Amyloid beta from axons and dendrites reduces local spine number and plasticity. Nat Neurosci 13(2):190-196

100. Winblad B, Poritis N (1999) Memantine in severe dementia: results of the 9M-best study (benefit and efficacy in severely demented patients during treatment with memantine). Int J Geriatr Psychiatry 14(2):135-146

101. Zhou X et al (2013) NMDA receptor-mediated excitotoxicity depends on the coactivation of synaptic and extrasynaptic receptors. Cell Death Dis 4:e560

\section{Ready to submit your research? Choose BMC and benefit from}

- fast, convenient online submission

- thorough peer review by experienced researchers in your field

- rapid publication on acceptance

- support for research data, including large and complex data types

- gold Open Access which fosters wider collaboration and increased citations

- maximum visibility for your research: over $100 \mathrm{M}$ website views per year

At $\mathrm{BMC}$, research is always in progress.

Learn more biomedcentral.com/submissions 